\title{
Targeting autophagy using metallic nanoparticles: a promising strategy for cancer treatment
}

\author{
Marco Cordani ${ }^{1,2} \cdot$ Álvaro Somoza $^{1,2}$ (1)
}

Received: 26 October 2018 / Accepted: 20 November 2018 / Published online: 27 November 2018

(c) The Author(s) 2018

\begin{abstract}
Despite the extensive genetic and phenotypic variations present in the different tumors, they frequently share common metabolic alterations, such as autophagy. Autophagy is a self-degradative process in response to stresses by which damaged macromolecules and organelles are targeted by autophagic vesicles to lysosomes and then eliminated. It is known that autophagy dysfunctions can promote tumorigenesis and cancer development, but, interestingly, its overstimulation by cytotoxic drugs may also induce cell death and chemosensitivity. For this reason, the possibility to modulate autophagy may represent a valid therapeutic approach to treat different types of cancers and a variety of clinical trials, using autophagy modulators, are currently employed. On the other hand, recent progress in nanotechnology offers plenty of tools to fight cancer with innovative and efficient therapeutic agents by overcoming obstacles usually encountered with traditional drugs. Interestingly, nanomaterials can modulate autophagy and have been exploited as therapeutic agents against cancer. In this article, we summarize the most recent advances in the application of metallic nanostructures as potent modulators of autophagy process through multiple mechanisms, stressing their therapeutic implications in cancer diseases. For this reason, we believe that autophagy modulation with nanoparticle-based strategies would acquire clinical relevance in the near future, as a complementary therapy for the treatment of cancers and other diseases.
\end{abstract}

Keywords Nanomedicine $\cdot$ Nanomaterials $\cdot$ Cancer therapy $\cdot$ Autophagy

\section{Introduction}

Cancer is a complex set of diseases that represent almost one-third of the leading causes of death and disability worldwide [1]. Although the tumors widely differ from their genetic and molecular basis, phenotypic manifestations and variability on the prognosis, they share common hallmarks such as self-sustained proliferative abilities, sustained angiogenesis, drastic metabolic alterations, or the capability to

Marco Cordani

marco.cordani@imdea.org

$\triangle$ Álvaro Somoza

alvaro.somoza@imdea.org

1 Instituto Madrileño de Estudios Avanzados en Nanociencia (IMDEA Nanociencia), CNB-CSIC-IMDEA Nanociencia Associated Unit "Unidad de Nanobiotecnología", Madrid, Spain

2 Institute for Advanced Studies in Nanoscience (IMDEA Nanociencia), Faraday 9, Office 129, Lab 137 Ciudad Universitaria de Cantoblanco, 28049 Madrid, Spain invade surrounding tissues and metastasize [2]. In addition, a relevant number of human tumors display dysregulation on autophagy, the essential cellular housekeeping mechanism that enables eukaryotic organisms to maintain cellular homeostasis and normal function by degrading and turning over damaged organelles and misfolded proteins [3, 4]. In tumors with enhanced autophagy, its inhibition affects tumor cell survival under metabolic and chemotherapy stresses. On the other hand, excessive autophagy induction by cytotoxic drugs or autophagy inducers may also lead to autophagic cell death. Hence, the modulation of autophagy represents a therapeutic approach for different types of cancers [5]. Traditional chemotherapeutic drugs present a variety of side effects such as low specificity, irregular distribution in tissues and organs, rapid drug clearance and biodegradation [6]. Therefore, new cancer treatments are desired, such as those derived from nanomedicine. This field of research can be defined as nanotechnology applied to human health and provides novel approaches for treating many human diseases, including cancer [7]. The majority of nanomaterials exhibit unique properties that make them useful for a 
variety of biotechnological applications. These properties have been exploited to create effective therapeutic and/or diagnostic tools $[8,9]$. Nanomaterials can be used as cytotoxics, and/or enhancers of standard chemotherapies, as well as, drug delivery systems, reducing the side effects of conventional drugs [10,11]. A number of nanomedicines have been assessed in clinical trials in combination with various therapeutic agents, mainly anticancer drugs, and many more are expected to be approved by the Food and Drug Administration (FDA) in the near future $[12,13]$. Interestingly, several studies have reported the ability of various types of nanomaterials to exert a cytotoxic effect by modulating the autophagy process $[14,15]$. Despite the risk of their inherent toxicity in immunity cells, and cardiovascular and neurological systems, nanomaterials may serve as therapeutic agents against autophagy-related diseases [14, 15]. In this review, we summarize the recent studies on the capability of nanostructures to promote cell death by autophagy overstimulation in cancerous cells. Furthermore, to better introduce the reader to this topic we have included some sections dealing with autophagy, where its mechanisms and implications are detailed, as well, as some uses of nanomaterials in nanomedicine.

\section{Macroautophagy}

Macroautophagy (commonly referred to as autophagy) is an intracellular degradative process by which damaged macromolecules and organelles are targeted by autophagic vesicles to lysosomes and then eliminated. Autophagy is crucial to maintain primary biological activities during cellular stresses, such as nutrient starvation [16]. Once autophagy is activated, the cellular components are embedded into double-membrane vesicles (autophagosomes), which fuse with lysosomes to form an autophagolysosome structure to degrade its contents by lysosomal hydrolases providing a nutrient source for maintaining vital cellular activities [17]. Autophagy requires the activation of some autophagyrelated genes (ATGs), which play a pivotal role in the formation of double-membrane autophagosome vesicles and the stimulation of the autophagy machinery $[18,19]$. Vesicular protein sorting 34 (Vps34), belonging to the class III PI-3 kinases, has been described to interact with Beclin-1 and other autophagy-related proteins playing a critical role in autophagy initiation [19]. Importantly, the ubiquitin-like conjugation systems are necessary for the activity of specific ATG proteins [20]. In particular, the mammalian homolog of ATG8, also called LC3B, is expressed as a full-length cytosolic protein that, upon induction of autophagy, is proteolytically cleaved by ATG4, a cysteine protease, to generate LC3B-I. The carboxy-terminal glycine exposed by ATG4dependent cleavage is then activated in an ATP-dependent manner by the E1-like ATG7 and transferred to ATG3, to generate the active isoform LC3B-II. The recruitment and integration of LC3B-II into the growing phagophore are dependent on ATG5-ATG12 interaction, favoring the binding of LC3B-II on both internal and external surfaces of autophagosomes, where it plays a role in both fusion of membranes and in selecting cargo for lysosomal degradation [21] (Fig. 1).

\section{AMPK and mTOR: the regulators of autophagy}

The nutrient energy sensor AMP-activated protein kinase (AMPK) is the master regulator of autophagy. It inhibits mTORC1 through phosphorylation of TSC2 and Raptor in response to cellular energy cues [22, 23] and the AMPKdependent ULK1 phosphorylation is a required step to trigger the autophagy machinery [24]. Under energetic stress, autophagy initiators unc-51-like kinase 1 (ULK1) complex promotes autophagy by targeting several downstream crucial autophagy effectors involved in the initiation of the process, such as the actin-associated motor protein myosin II and ATG9 [24]. Mammalian target of rapamycin (mTOR), a serine/threonine protein kinase with large molecular size, belongs to the phosphatidylinositol kinase-related kinase (PIKK) family and it is implicated in the regulation of multiple cellular processes including cell growth, cell cycle, cell survival, as well as autophagy. The observation that treatment with mTOR inhibitors, such as rapamycin, is sufficient to induce autophagy even in the presence of nutrients represents valid evidence for the conclusion that mTOR complex is a powerful repressor of autophagy [25]. mTOR is composed of two multiprotein enzymatic functional complexes, mTORC1 and mTORC2 [26]. Contrarily to $\mathrm{mTORC} 2$, mTORC 1 is sensitive to the inhibition by rapamycin, and it is directly regulated by the cellular nutrient status, including growth factors and amino acid availability, playing essential roles in the regulation of protein translation and autophagy [26]. Although mTORC2 was discovered recently, it has already been demonstrated that mTORC2 plays a role in chaperone-mediated autophagy [27] and could activate autophagy via FoxO3 [28]. Interestingly, mTORC2 phosphorylates and activates Akt, which has a role in the regulation of cell proliferation, survival, metabolism, and transcription [26]. Genetic and biochemical studies demonstrated that the inhibition of ULK1 by mTOR is a crucial mechanism involved in autophagy repression [29]. Importantly, recent studies showed that mTOR can phosphorylate ULK1 on Ser757 to favor autophagy blockage [24]. Several studies indicate that wild-type p53 protein triggers autophagy in cancer cells through various mechanisms including the stimulation of AMPK, the inhibition of the mTOR (by upregulation of PTEN and TSC1), and the induction of DRAM1 [30]. The functional interplay between 

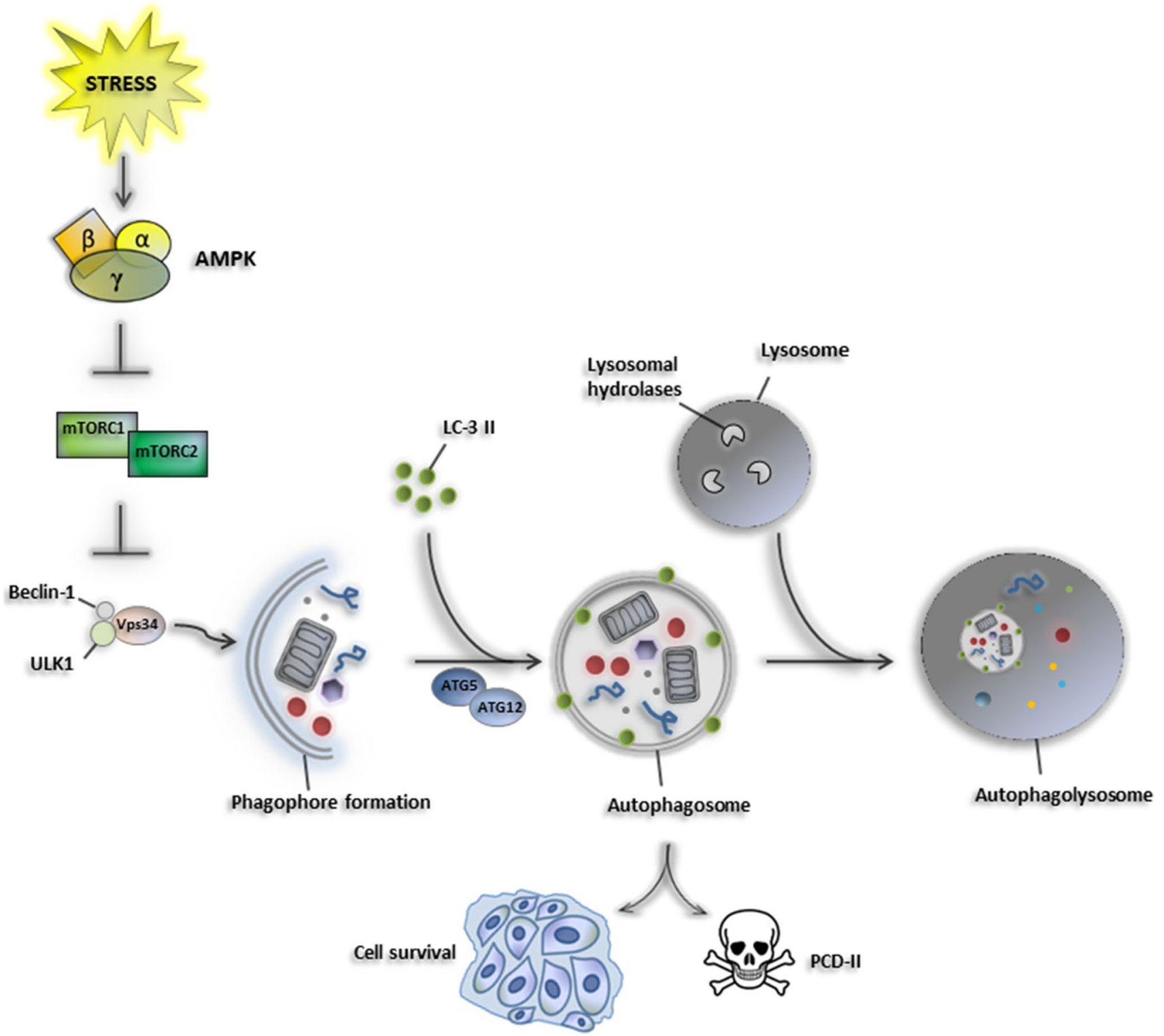

Fig. 1 Mechanism of macroautophagy. Cellular stresses induce AMPK signaling that inhibits the anti-autophagic mTOR complex (mTORC1 and mTORC2). Consequently, Beclin-1, ULK1, and $\mathrm{Vps} 34$ mediate phagophore formation and autophagy initiation. Recruitment of LC-3 II into the growing phagophore is dependent on ATG5-ATG12 interaction which favors the binding of LC3B-

AMPK and wtp53 is a well-described mechanism involved in tumor suppression. Indeed, the stimulation of AMPK by energy stress promotes the phosphorylation and activation of wtp53 [31, 32]. Moreover, AMPK can increase both the activity and the stability of wtp53 through direct phosphorylation of p53 and inactivation of MDMX-mediated ubiquitination process, thus prolonging the half-life of wtp53 itself [33]. Wtp53 may, in turn, increase AMPK activity through transcriptional activation of the gene encoding the $\beta$ subunit of the enzymatic complex [34] and Sestrins [35],
II on both internal and external surfaces of autophagosomes, where it plays a role in both fusion of membranes with lysosomes and in selecting cargo for lysosomal degradation. Depending on the nature of the stimulus and by cellular context, autophagy acts as a pro-survival mechanism by maintaining vital cellular activities, or drives cell death-type-II, thus acting as tumor suppressor event

providing positive feedback that sustains an autophagic AMPK signaling.

\section{Mitophagy: a specialized form of autophagy}

Mitochondria are cellular organelles playing a crucial role in energy metabolism, regulation of cell signaling and apoptosis in eukaryotic cells [36]. To maintain cellular homeostasis, the cell has evolved complex systems for the quality control and clearance of mitochondria. Mitophagy is a 
selective form of autophagy, by which dysfunctional or damaged mitochondria are selectively targeted by autophagosomes and delivered to lysosomes to be recycled by the cell. Hence, mitophagy represents an essential quality control mechanism to ensure mitochondrial network's integrity and functionality. Similarly to macroautophagy, mitophagy is tightly regulated by a variety of proteins controlling each phase of the process, to ensure the selective sequestration of those mitochondria that need to be eliminated, in the forming autophagosome. Efficient mitophagy occurs during some vital biological processes through Parkin-dependent and Parkin-independent pathways, and allows the damaged organelles to be targeted into the nascent autophagosome, without affecting the entire mitochondrial network $[37,38]$. However, an extensive or uncontrolled mitophagy can lead to bioenergetic failure, whereas excessive mitochondrial biogenesis can generate high levels of reactive oxygen species (ROS) and promote apoptosis or cell survival depending on the type of stimulus and the cellular context [38]. Therefore, the maintenance of a balanced healthy mitochondrial population through both processes is essential for cellular function and survival [39]. Defects in mitophagy machinery are linked to most of the neurodegenerative diseases [40], to tumorigenesis, neoplastic progression and chemoresistance $[41,42]$. Therefore, we hypothesize that pharmacological modulation of mitophagy could represent a potent strategy against many human diseases.

\section{Autophagy in cancer}

Autophagy has been described to play a role in physiological processes, mammalian development and a variety of human diseases, including cancer, neurodegenerative diseases and muscular disorders [43]. Autophagy regulation is strictly interconnected with the aberrant setting of cancer cell metabolism as revealed by the fact that mTOR and AMPK pathways are both the master regulators of autophagy and the most critical sensors of the cellular energy status [44]. In particular, the mTOR complex stimulates anabolic biosynthesis for cancer cell growth and inhibits autophagy, while AMPK signaling triggers the degradation of macromolecules, including lysosomal autophagic catabolism [45]. The role of autophagy in regulating cancer cell death or survival remains highly controversial and it is likely reliant on the tumor type, the stage of neoplasia and the cellular context, as well as by metabolic context in which the cells lie [46].

Some studies support the idea that, in established tumors, constitutive autophagy may have a protective role in cancer cells by removing damaged organelles or recycling misfolded macromolecules [47]. In support of this hypothesis, several studies report that autophagy tries to fulfill the high metabolic demands of the proliferating tumor cells exposed to stressful conditions, such as nutrient deprivation, oxidative stress, hypoxia, or in response to therapy [46, 48]. Hypoxic microenvironments trigger HIF- $1 \alpha$-dependent and -independent autophagy, which also contributes to tumor survival [49]. Interestingly, cancers harboring activating KRAS mutations have a high basal rate of autophagy, even in growth conditions [50]. It has been reported that pharmacological and genetic inhibition of autophagy results in tumor regression in pancreatic cancer xenografts and genetic mouse models [50, 51]. Thus, by enhancing stress tolerance and providing an alternative nutrient source by which cancer cells can meet their massive nutrient and energy demands, autophagy appears to serve as a pro-survival mechanism for tumor cells.

However, it is also well established that cancer cells having uncontrolled autophagy can also undergo cell death, also called cell death-type II, likely due to excessive degradation of cellular constituents and organelles required for homeostasis of the cells. Hence, autophagy has been widely established as a tumor-suppressive mechanism, and cancer cells can escape from extensive autophagic cell death resulting in the enhancement of ROS production, genomic instability, and tumor progression [54]. Defects in autophagy cause the accumulation of abnormal mitochondria that are a potential source of ROS that lead genomic instability, and cancer initiation and progression [52]. Moreover, autophagy dysfunctions cause also activation of the DNA damage response, DNA copy number variations, and genetic instability, which lead to the acquisition of genome mutations that drive tumorigenesis [53]. This situation of chronic tissue damage also provokes an inflammatory response that can, in turn, sustain tumor growth through cytokine and chemokine productions [54]. Thus, tumor promotion conferred by autophagy defects may result from both mutagenesis and the creation of an inflammatory environment. In this sense, it has been reported that mice having monoallelic deletion of the autophagy-related gene beclin 1 develop spontaneous tumors. Allelic loss of beclin1 was also observed in 40-75\% of breast, ovarian, and prostate cancers [3, 55]. In addition, accumulation of autophagy adaptor protein, p62/SQSTM1, as a result of the inhibition of autophagy, was reported to be responsible for the tumorigenesis by multiple mechanisms [56].

This evidence strongly suggests that autophagy is an important mechanism that suppresses tumor initiation and, when impaired, may lead to tumorigenesis. Recently, several studies have demonstrated that mutant p53 proteins exert oncogenic ability that leads to high genomic instability, reduced response to chemotherapy and generally poor clinical outcome of cancer patients [57]. Interestingly, contrarily to the wild-type counterpart, mutant $\mathrm{p} 53$ proteins can inhibit autophagy machinery through the stimulation of mTOR signaling pathway $[58,59]$ and the inhibition of AMPK [60, 61]. This oncogenic ability represents an essential turning 
point to sustain cancer cell proliferation and growth. On the other side, autophagy can trigger mutp53 protein degradation in a functional interplay that can regulate tumor progression and the response to antitumor therapies [62].

\section{Autophagy in other diseases}

Neurodegenerative diseases, such as Parkinson's disease (PD), Alzheimer's disease (AD), Huntington's disease (HD), and amyotrophic lateral sclerosis (ALS), are characterized by the progressive loss of neurons and/or neuronal functions. These syndromes are developed by the presence of aggregate-prone neurotoxic proteins, in the form of aggresomes and/or inclusion bodies, as well as by the presence of dysfunctional mitochondria [63]. In this regard, autophagy protects against neurodegenerative diseases acting as a quality-control system and by removing protein aggregates and damaged organelles. Therefore, it represents an essential process for the maintenance of neuronal homeostasis [64]. Recent findings have highlighted that autophagy has a crucial role also in the control of muscle mass [65]. Overstimulated autophagy is harmful to myofiber health and is involved in some inherited muscle diseases [65]. However, also defective autophagy clearance favors the aggregation of misfolded proteins and damaged organelles, and contributes to the pathogenesis of different forms of muscular dystrophies and congenital myopathies [65-67]. Interestingly, recent observations suggest that re-establishing a proper autophagic flux with pharmacological treatments might represent a promising strategy for counteracting muscle loss in muscular disorders [68]. Autophagy pathway plays a central role in the cellular quality control, metabolic adaptation and clearance of misfolded proteins and/or damaged organelles in a plethora of human diseases, and the pharmacological modulation of this process may represent a valid therapeutic challenge [77].

\section{Current cancer treatments based on autophagy modulation}

In tumors with enhanced autophagy, as a mechanism of survival and chemoresistance, the inhibition of autophagy can suppress the ability of tumor cells to survive under cellular metabolic stress $[69,70]$ making them more prone to initiate cell death mechanisms. In this sense, there are a variety of examples showing that autophagy inhibitors, when used in combination with anticancer drugs, may sensitize chemoresistant cells, thus inhibiting tumor survival $[47,71]$. For example, it has been reported that inhibition of autophagy function by depletion of $\operatorname{Atg} 5, \operatorname{Atg} 7$ or beclin 1 may revert the acquired resistance against tamoxifen in HER-positive breast cancer cells [72]. The combinatorial treatment consisting of autophagy inhibitor 3-methyl-adenine (3-MA) and trastuzumab (Tmab) in HER2-positive breast cancer cells can increase the potency of chemotherapy [73]. Increased autophagy is also associated with cisplatin resistance in ovarian cancer cells, and Atg5 deletion in these cells induces apoptotic cell death [74].

Among the multiple compounds that inhibit the different phases of autophagy, nowadays the only clinically approved autophagy inhibitor by the FDA is the anti-malarial chloroquine (CQ) and its derivatives, such as hydroxychloroquine (HCQ) [75]. HCQ belongs to the class of lysosomotropic agents that can inhibit lysosomal acidification and prevent the degradation of autophagosomes, thereby suppressing autophagy [76]. HCQ has been shown to have antineoplastic effects in numerous preclinical experiments when combined with other agents [77]. In renal cell carcinoma lines, HCQ enhanced the cytotoxicity of mTOR inhibitor, such as temsirolimus, promoting apoptosis and causing the downregulation of phospho-S6 through a mechanism not found in other autophagy inhibitors, such as bafilomycin A1 [78]. In breast cancer cells, the combination of HCQ and tamoxifen (TAM) was more effective at inhibiting autophagy than monotherapy in estrogen receptor-positive (ER+) breast cancer cell lines [79]. Frequently, cancer cells treated with chemotherapy drugs exhibit autophagy induction that serves as survival mechanism. However, excessive autophagy induction upon cytotoxic drug treatment or using autophagy inducers may also lead to autophagic cell death. It has been reported that glioblastoma cells resistant to apoptosis die when treated with alkylating agents such as temozolomide and tyrosine kinase inhibitors such as dasatinib, where both induce autophagy [80]. Similarly, histone deacetylase (HDAC) inhibitors have also shown autophagy-inducing potential as one of its anticancer effects [81]. Proteasome inhibitors (PI) have also been shown to stimulate autophagy. Bortezomib, a PI used in the treatment of multiple myeloma and mantle cell lymphoma, has been shown to increase the early formation of autophagosomes and LC3-II, demonstrating the inducing effects on autophagy [82]. A well-known class of autophagy inductors includes analogs of the mTOR inhibitor rapamycin, such as temsirolimus and everolimus. These compounds, used alone or in conjunction with chemotherapy drugs, show an antiproliferative effect in mantle cell lymphoma and acute lymphoblastic leukemia by overstimulating autophagy, which might cause tumor cell death [83, 84]. Everolimus has been approved for use by the FDA as an angiogenesis inhibitor in renal cell carcinoma, advanced breast cancer, and pancreatic neuroendocrine tumors $[85,86]$. However, it is not clear whether the induction of autophagy by everolimus contributes to its anti-angiogenesis ability. However, in clinical trials, current targeted anticancer treatments based exclusively on mTOR inhibition have demonstrated high resistance rates [87, 88] (Table 1). Numerous ongoing phase I/II clinical trials are investigating the combination of HCQ 


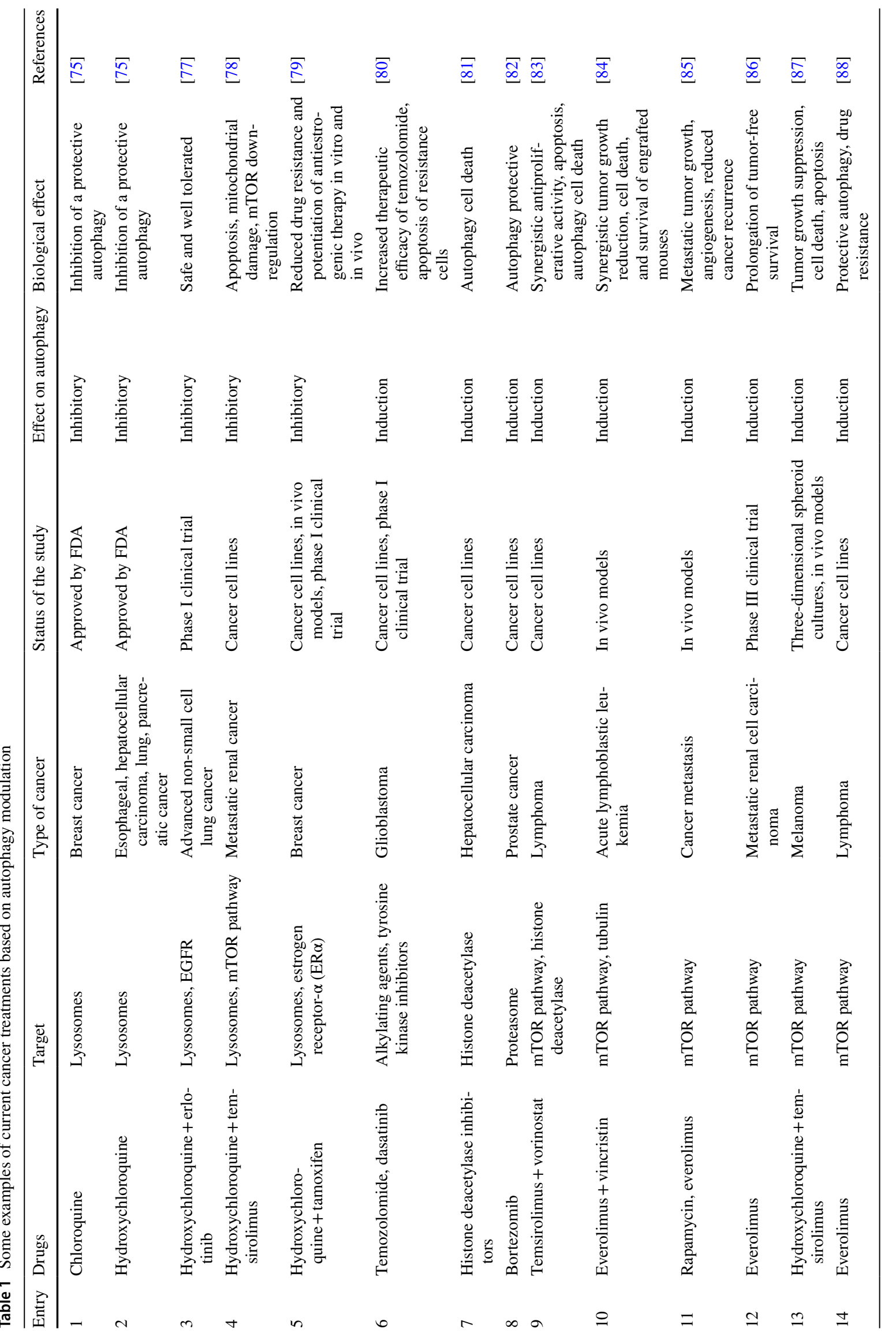


with mTOR inhibitors in renal cell cancer, multiple myeloma and advanced solid tumors as reviewed by Duffy et al. [71]. The large number of ongoing trials demonstrates the enormous relevance that autophagy modulation can have, in combinatory treatments, to overcome the resistance to existing cancer therapies (Fig. 2).

\section{Nanomaterials as therapeutic tools}

Recent progress in nanotechnology offers plenty of tools to fight cancer with innovative, personalized and efficient therapeutic agents by overcoming barriers or drawbacks usually encountered with traditional drugs [89]. The recent advances in the field of chemistry and material science have produced nanomaterials which are expected to improve the treatment of many diseases otherwise resistant to the traditional therapeutic approaches. Nanomaterials can act as cytotoxics and/or enhance the efficacy of standard chemotherapies. Moreover, they represent novel drug delivery systems thereby decreasing the side effects of conventional drugs. These nanomaterials exhibit unique physical, chemical, mechanical and optical properties that make them suitable as novel and powerful therapeutic tools. Depending on their morphology, size and chemical properties, nanomaterials are broadly divided into various categories, including liposomes, carbon-based materials, polymers, metals, metals oxide, and ceramics. Most of these nanomaterials are used as nanocarriers to deliver therapeutic molecules, such as drugs, proteins or nucleic acids [90-99].

One of the major challenges of nanomedicine consists of developing drug delivery systems to transfer drugs, proteins,

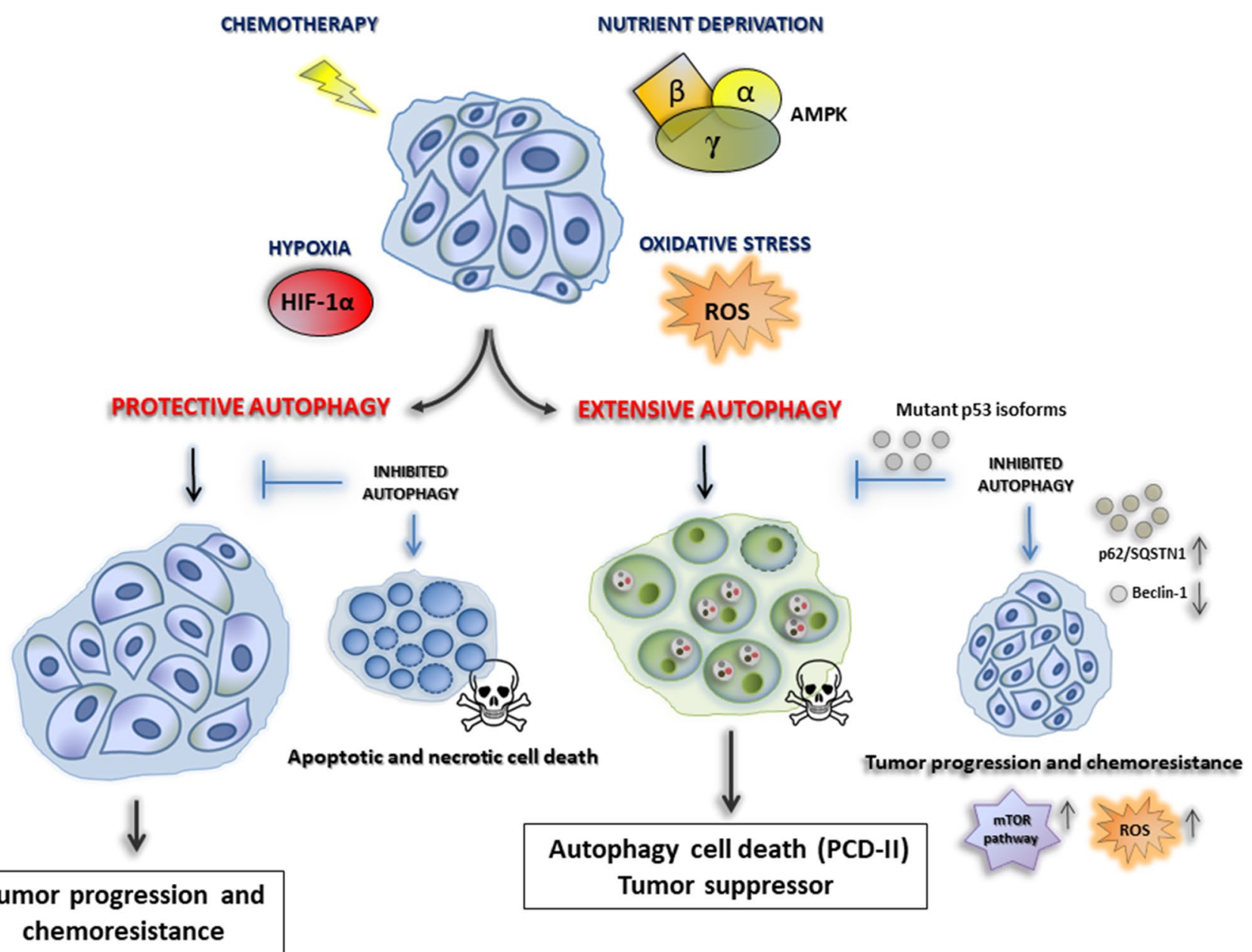

Fig. 2 The dual role of autophagy in cancer. A variety of cellular stresses, including (1) nutrient deprivation, (2) oxidative stress, (3) hypoxia and (4) chemotherapy, can result in the induction of a protective autophagy leading tumor progression and chemoresistance. However, the same stresses can also induce and autophagy with tumor suppressor role. Indeed, cancer cells having an uncontrolled extensive autophagy can also undergo cell death-type II, likely due to excessive degradation of cellular constituents and organelles. Importantly, the inhibition of protective autophagy leads to apoptotic and necrotic cell death. In contrast, the inhibition of autophagy cell death (for instance by oncogenic mutant p53 isoforms) may lead to tumorigenesis through mTOR signaling and ROS 
enzymes or antibody into specific target sites without affecting healthy tissues. The primary physical, chemical, and biological advantages in the use of nanocarriers include the nanoscale sizes, high surface-to-volume ratios, favorable drug release profiles and targeting modifications [6]. Interestingly, nanocarriers can passively accumulate in the leaky vasculature, typical of tumor tissues in a manner known as the enhanced permeability and retention effect (EPR) [100]. Nanocarriers may also be conjugated with specific ligands, to utilize active targeting mechanisms [101]. This allows them to reach specific tissues and release drugs in a stable and controlled manner. Therefore, through active targeting, the use of nanomaterials in drug delivery can modify the pharmacokinetic and pharmacodynamic profiles of drugs, thereby enhancing their therapeutic index [100, 102]. Microenvironmental stimuli can trigger the release of drugs by evoking a change in the nanocarriers, to ensure specific toxicity to the target tissue, while does not affect the healthy tissue [10]. Changes in $\mathrm{pH}$, redox, ionic strength, and stress in target tissues are examples of internal stimuli $[7,13]$. External stimuli, including temperature, light, ultrasound, magnetic force, and electric fields, also can trigger the release of drugs [7] (Fig. 3).

Among the different nanostructures, metallic nanoparticles are particularly relevant due to their inherent reactivity, which can be used for therapeutic purposes, such as hyperthermia. Hyperthermia-based approaches [103] consist of exposing the body to high temperatures to kill cancer cells or sensitizing them to the effects of radiation and certain anticancer drugs. The use of metallic nanoparticles allows for the application of a variety of techniques such as laser, ionizing radiation and microwaves, to induce heat at the nanoparticles area [103]. Magnetic hyperthermia allows to remotely induce local heat using the magnetic energy losses of magnetic nanoparticles under an alternate magnetic field (AMF), thus drastically reducing the harmful side effects at

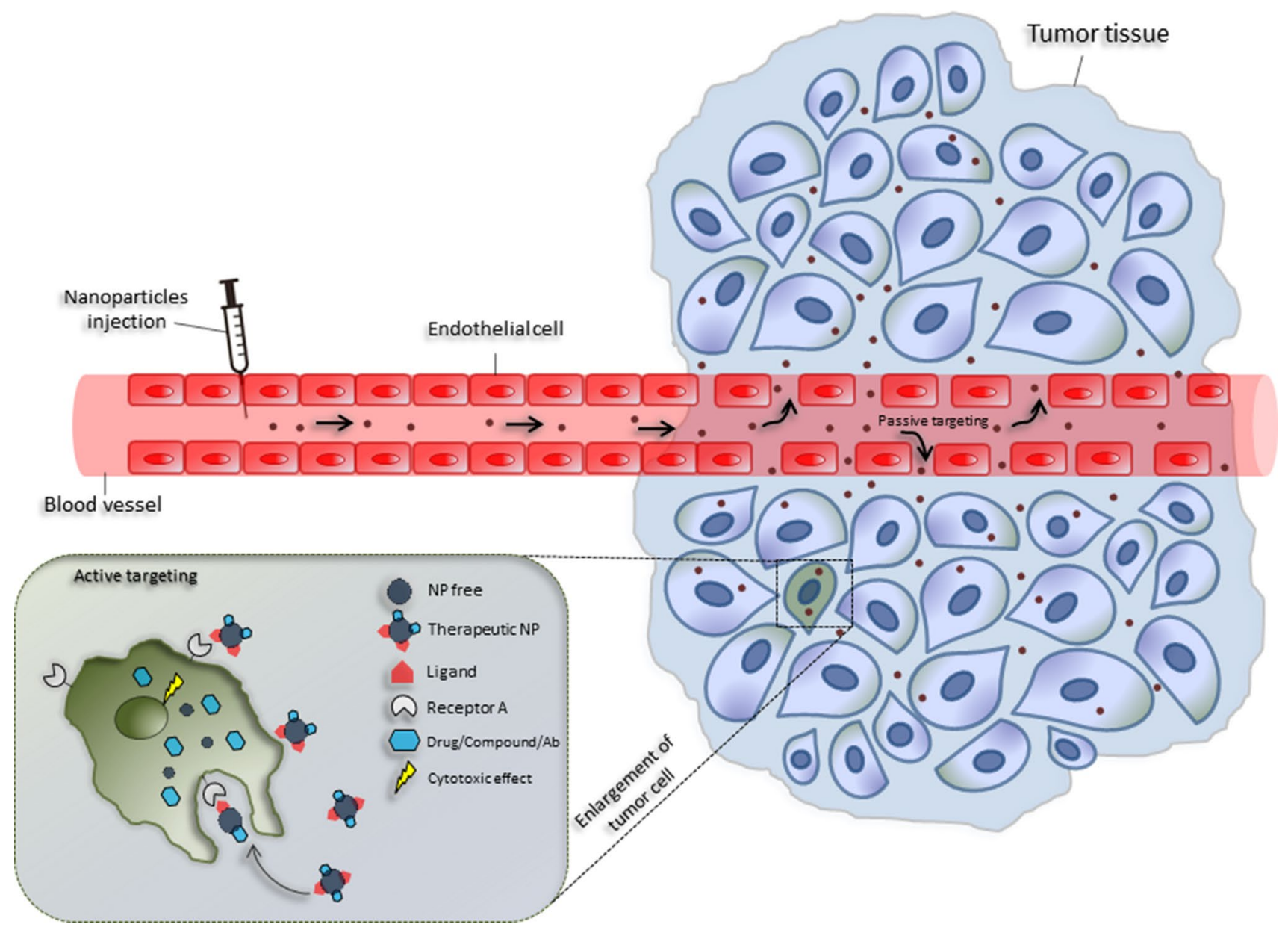

Fig. 3 Passive and active targeting of nanoparticles in cancer treatment. Passive tumor targeting is achieved by extravasation of nanoparticles through increased permeability of the tumor vasculature (EPR effect). Active tumor targeting (left inset) can be achieved by functionalization of nanoparticles with targeting ligands that promote cell-specific recognition and binding. Once internalized, the nanoparticles can express their cytotoxic potential by releasing the drug and/ or another compound 
the surrounding healthy tissues [104]. Importantly, a number of studies describe magnetic hyperthermia as a very attractive adjuvant strategy to radiation and chemotherapy in cancer treatment [105]. Alternatively, by exposing metallic nanoparticles to laser radiation near their plasmon-resonant absorption band, it is possible to produce local heating of nanoparticle-labeled cells without harming surrounding healthy tissues. Such some promising approaches, which induce the photothermal effect in vitro and in vivo, have been developed over the last years. They include plasmonic photothermal therapy (PPTT) [106], and red and nearinfrared (NIR) laser light irradiations [107]. Interestingly, massive cancer cell death, reduction of tumoral volume and general improvements in survival have been demonstrated when the gold nanoparticles are actively targeted to tumors in mice over passively targeted nanoparticles [108-111].

\section{Targeting autophagy with metal-based nanoparticles as therapy in cancer diseases}

In this section, we summarize the most recent studies describing the ability of metallic nanoparticles to overstimulate autophagy and mitophagy in cancer cells selectively. This occurs through the dysregulation of some cellular signaling pathways without significantly affecting the level of autophagy in noncancerous cells. The effect of several nanomaterials on autophagy/mitophagy modulation represents an exciting therapeutic approach against different human tumors (Fig. 4).

\section{Silver-based nanoparticles}

Different studies showed the enormous therapeutic potential of silver nanoparticles (Ag-NPs) against a plethora of cancer cells. It has been reported that these nanomaterials can modulate autophagy acting as cytotoxic agents itself, in combination with other treatments, as well as nanocarriers to deliver therapeutic molecules [112-120]. For example, it has been shown that Ag-NPs, embedded into a specific exopolysaccharide (EPS), exert a cytotoxic effect against a panel of cancer cell lines. This occurs through the promotion of ROS which, in turn, induced cell death through apoptosis and autophagy stimulations. These observations were further confirmed in SKBR3 cells after Ag-NPs-EPS exposure in which the induction of autophagic markers was detected by fluorescence microscopy and western blot indicating a prominent mechanism of autophagic cell death [112].

In another study, Ag-NPs have been observed to have a higher cytotoxic effect on PANC1 cancer cells compared to the non-tumor cell of the same tissue. In particular, AgNPs decreased the viability of PANC-1 cells and stimulated apoptotic and autophagic cell death more significantly than non-tumor cells. Moreover, the authors observed that the protein level of autophagy marker LC3-II increased substantially in PANC-1 cells treated with Ag-NPs, thus indicating that the apoptotic and necroptotic cell death is occurring with autophagy in adenocarcinoma pancreatic cancer cells [113].

In a related report, Cisplatin and a reduced graphene oxide-silver nanoparticle nanocomposite (rGO-Ag-NPs) were assessed in HeLa cancer cells. Interestingly, the combination of Cis and rGO-Ag-NPs resulted in more pronounced effects on the expression of autophagy genes and in the accumulation of autophagosomes and autophagolysosomes, which were associated with the generation of ROS and cell death. These findings demonstrate that $\mathrm{rGO}-\mathrm{Ag}$ NPs can potentiate Cis-induced cytotoxicity, apoptosis, and autophagy in HeLa cells, and hence rGO-Ag-NPs could be potentially applied to cervical cancer treatment as a powerful synergistic agent with Cis or any other chemotherapeutic agents [114]. Notably, also the combination of Salymicin (Sal) and Ag-NPs showed a substantial synergistic effect on cytotoxicity and in the accumulation of autophagolysosomes in A2780 ovarian cancer cells. The induction of massive autophagy, in turn, led to mitochondrial dysfunction and cell death, thus representing a relevant therapeutic strategy for the treatment of ovarian cancer [115].

Moreover, it has been found that the combination of Ag-NPs and radiotherapy significantly enhanced cytotoxic effects in U251 glioblastoma cells and orthotopic mouse brain tumor model. In addition, LC3-II protein level, acridine orange (AO) and monodansylcadaverine (MDC) staining revealed that autophagy was strongly upregulated following the treatment of Ag-NPs with ionizing radiation, suggesting that modulation of the autophagy process may improve glioblastoma therapeutic outcome [116]. Transcription factor EB (TFEB) is a master regulator of lysosomal biogenesis, and it has been reported to regulate autophagy by upregulating a cluster of autophagic genes, including MAPLC3B, SQSTM1, UVRAG, WIPI, VPS11, VPS18, and ATG9B [121, 122]. Recently, Ag-NPs have been shown to reduce the expression of TFEB in A459 lung cancer cells, thus affecting lysosome function and autophagic flux, and leading cellular damage [123].

\section{Gold-based nanoparticles}

Gold nanoparticles (Au-NPs) have been extensively explored in biomedical research as drug delivery scaffolds, because of their low toxicity and immunogenicity [124, 125], good biocompatibility and excellent stability [126]. Remarkably, the surface of Au-NPs can be easily modified with multiple agents including chemotherapeutics, oligonucleotides, and proteins, making them excellent delivery vehicles. 


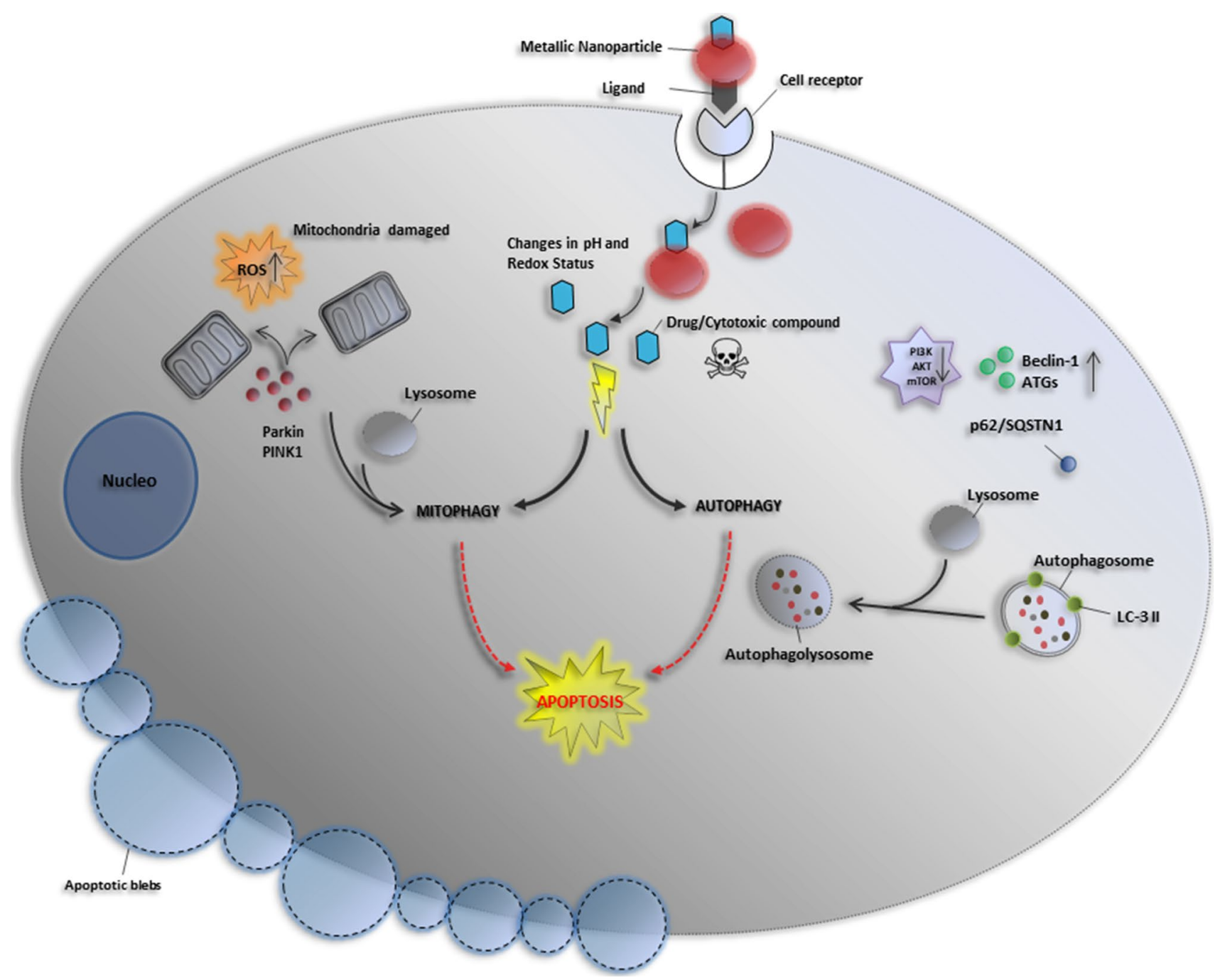

Fig. 4 Cytosolic delivery of drug-loaded metallic nanoparticles via receptor-mediated endocytosis and its effect on autophagy and mitophagy modulation. The metallic nanoparticles, once internalization via receptor-mediated endocytosis, release the drugs or other compounds loaded, thus exerting a cytotoxic effect against cancer cells. The release occurs as a consequence of some cellu-

It has been reported that $\mathrm{pH}$-sensitive polymeric nanoparticles with gold(I) induce cell death in MCF7 breast cancer cell death through regulation of oxidative stress and autophagy [127]. A recent study describes the development of SMI\#9-tethered Au-NPs using a chemical strategy that allows the intracellular release of SMI\#9, a small inhibitor of Rad6, a central player in DNA damage tolerance, post-replication DNA repair mechanism and mitochondrial stability $[128,129]$. The authors of this study observed an increase in autophagy and apoptotic markers in SUM1315 triple-negative breast cancer (TNBC) cells after treatment with SMI\#9-AuNPs, suggesting an essential role for Rad6 in assuring the survival of cancer cells [130]. lar environmental stimuli, such as changes in $\mathrm{pH}$ and redox status by evoking changes in the nanocarrier structure. The toxic effect is exerted in various manners by inducing mitochondrial damage, and autophagy and mitophagy processes that culminate with apoptotic and autophagic cell death

In a related study, gold nanoparticles were modified with the snake venom protein toxin NKCT1 (Au-NPs-NKCT1) and tested in human leukemic U937 and K562 cell lines [131]. The authors reported that Au-GNPs-NKCT1 treatment exerts its cytotoxic potential by inducing a caspase 3-mediated apoptosis and an autophagic cell death response due to the dysregulation of AKT/mTOR signaling pathways. Therefore, the conjugation of Au-NPs with NKCT1 represents a promising strategy to develop therapies from natural resources such as snake venoms [131].

It has been reported that Au-NPs, in combination with tumor necrosis factor (TNF)-related apoptosis-inducing ligand (TRAIL), were able to promote a relevant Drp1-mediated mitochondrial damage leading apoptosis, autophagy 
and mitophagy activation [132]. In support of this, the authors found that mitophagy markers PINK1 and Parkin were recruited into mitochondrial fractions and autophagy signature was detected in Calu-1 cells after combined treatment [132]. Hence, autophagy and mitophagy activations in response to TRAIL combined with Au-NPs may represent a strategy to overcome TRAIL resistance that occurs in many tumors.

The epidermal growth factor receptor (EGFR) is overexpressed in 70-80\% of TNBC and has been emerging as a promising target for TNBC treatment [133]. In a recent report, the role of autophagy was assessed in the cytotoxicity induced by anti-EGFR antibody-conjugated gold nanoparticle (anti-EGFR-Au-NPs)-combined near infrared-photothermal therapy (NIR-PTT) in MDA-MB-231 cancer cells [134]. Interestingly, the cell death induced by anti-EGFR-Au-NPscombined NIR-PTT was rescued by treatment with 3-MA. Anti-EGFR-Au-NPs-combined NIR-PTT strongly induced autophagy as evidenced by autophagic vesicles and a significant increase in several autophagy-related markers, accompanying the inhibition of AKT/mTOR signaling pathway. In addition, in mouse xenograft tumors, anti-EGFR-Au-NPscombined NIR-PTT also increased LC3 and beclin-1 levels. These findings demonstrate that autophagy elicited by antiEGFR-GNs-combined NIR-PTT is an alternative cell death mechanism, resulting in most effective cancer therapy for EGFR-targeted TNBC [134].

Tmab is a humanized monoclonal antibody routinely used for patients with HER2-positive breast and gastric cancers that improves survival [135]. In a recent study, Au-NPs modified with Tmab were evaluated in NCI-N87 and MKN7 HER2-positive gastric cancer. Interestingly, the authors report that T-Au-NPs possessed specific HER2-based tumor selectivity and exerted a potent cytotoxic effect through the induction of autophagy mechanism that differs from those of the non-conjugated Tmab [136].

Quercetin $\left(3,3^{\prime}, 4^{\prime}, 5,7\right.$-pentahydroxy-flavone $)$ is a flavonoid found in a wide variety of plants and constituent in human diet [137]. Quercetin exhibits beneficial effects on human health and possesses selective antiproliferative and antitumor effects via apoptotic mechanisms on different human cancer cell lines [138]. It has been reported that gold-quercetin nanoparticles, stabilized by PLGA, induce autophagy cell death and apoptosis through dysregulation of signaling pathways in human liver, cervical and neuroglioma cancer cells [139-141].

Interestingly, it has been observed that monolayers of chiral molecules anchored on the surfaces of Au-NPs (DPAV-Au-NPs; L-PAV-Au-NPs) induced chirality-selective autophagy selectively in MDA-MB-231 cancer cells. Furthermore, the intratumoral injection of D-PAV-Au-NPs suppresses the tumor growth without side effects in vivo [142]. This specific effect was likely attributed to the chirality-variant ROS generation, cellular uptake, and their continuous autophagy stimulus.

Layered nanoparticles made with an iron core and a gold shell, Fe@Au, combine the strong magnetic susceptibility of pure iron and the passivating properties of the gold coating. In practice, the gold shell only delays the oxidation, rather than stopping it entirely [143]. Fe@Au-NPs have been reported to exert toxicity in oral and colorectal cancer cells through mitochondria-mediated autophagy and, therefore, have been proposed as a potential anticancer agent [144, 145].

\section{Metal oxide-based nanoparticles}

Zinc oxide nanoparticles (ZnO-NPs) are routinely used in industrial products, and more recently, they have been employed in biomedical and cancer applications due to the attractive chemical properties of these nanomaterials [146]. In a recent study, it has been reported that ZnO-NPs can induce significant cytotoxicity, apoptosis, and autophagy in SKOV3 ovarian cancer cells via induction of intracellular ROS and oxidative stress [147]. ZnO-NPs have also been shown to induce toxicity in CAL27 oral cancer cell lines by activating PINK1/Parkin-mediated mitophagy [148].

It has been reported that conjugation of ZnO-NPs with meso-tetra (4-carboxyphenyl) porphyrin (MTCP) could increase their cytotoxic effects through autophagy induction in MCF-7 and MDA-MB-468 breast cancer cells [149]. These reports strongly suggest a possible application of $\mathrm{ZnO}-\mathrm{NPs}$ as anticancer agents.

Iron oxide nanoparticles (IO-NPs) are widely used in biomedicine for their multi-functional properties of super-paramagnetism and biocompatibility as well as in cancer treatment due to their drug delivery and multi-imaging functions [150]. However, some issues concerning their therapeutic efficiency and biological safety limited their development and clinical translation.

Interestingly, IO-NPs have been reported to induce autophagy process through multiple mechanisms including lysosome impairment, mitochondrial damage, and ER stress [151].

IO/Au-NPs conjugated to anti-EGFR suppress lung tumor growth both in vitro and in vivo, by abrogating G2/M cellcycle arrest and inducing DNA damage, autophagy and apoptosis [152].

In an excellent study, researchers have developed chitosan chloride (HTCC)/alginate-encapsulated $\mathrm{Fe}_{3} \mathrm{O}_{4} \mathrm{NPs}$ (HTCC-MNPs) and applied them to multi-drug resistance (MDR) gastric cancer models. Interestingly, they reported that the novel HTCC-MNPs were more cytotoxic in both SGC7901 human gastric cancer cell line and MDR variant cell line (SGC7901/ADR) than to normal gastric epithelial cell line (GES). In addition, the co-localization 
of LC3 with lysosomal marker LAMP2 and an increased LC3-II/LC3-I ratio revealed the induction of autophagy by HTCC-MNPs. Therefore, these data indicated that autophagy was responsible for the cytotoxicity induced by HTCC-MNPs, highlighting that its modulation may have a role in treating MDR gastric cancer [153]. Moreover, IO-NPs have been shown to selectively induce significant autophagy-lysosome accumulation and cell death through dysregulation of Akt/AMPK/mTOR pathway and in a dispersity-dependent manner, in lung and cervix cancer cells but not in normal cells $[154,155]$.

Another study has reported that PEGylated IO-NPs caused severe cytotoxicity in SKOV3 human ovarian cancer cells through multiple mechanisms, such as ROS production and apoptosis induction. Notably, the authors observed changes in autophagosome formation when SKOV3 cells were exposed to PEGylated-IO-NPs by TEM imaging and by detecting the level of autophagy marker LC3-II. The authors concluded that autophagy induction could be a protective role against cytotoxicity IO-NPsinduced [156].

In another study, it has been shown that IO-NPs photothermal effect could lead to autophagy induction in both MCF-7 cancer cells and MCF-7 xenograft model, in a laser dose-dependent manner, and the inhibition of autophagy would enhance the photothermal cell killing by increasing cell apoptosis. Therefore, this work may provide a potential combination therapeutic approach of autophagy modulators and photothermal agents [157].

Cuprous (Cu-NPs) and copper oxide nanoparticles (CONPs), are other nanomaterials with biomedical application, which showed potential pharmacological effects on tumor therapy by inducing apoptosis, inhibiting metastasis and stimulating autophagic cell death in leukemia, melanoma, and lung and breast cancers [158-161].

In a study by Xia et al., Cu-NPs dramatically affect autophagy pathway in human cervical cancer cell lines, thus leading to inhibition of cell growth and apoptosis. In particular, the authors reported that $\mathrm{Cu}-\mathrm{NPs}$ could decrease the phosphorylation of AKT and mTOR, strongly suggesting that $\mathrm{Cu}-\mathrm{NPs}$ could induce autophagy through AKT/mTOR pathway. Moreover, they observed the increase of the autophagosome formation in a time- and concentration-dependent manner. Their work provides preliminary evidence of the therapeutic potential of CO-NPs in the treatment of cervical cancer [162]. Also, CO-NPs have been reported to induce autophagy in MCF7 human breast cancer cell line, in a time- and dose-dependent manner. The authors of the study hypothesize that autophagy induced by CO-NPs may serve as a cellular defense against their intrinsic toxicity, and inhibition of autophagy could be essential to induce apoptosis in breast cancer cells [163].

\section{Silica-based nanoparticles}

Many studies have demonstrated that amorphous silica nanoparticles (Si-NPs) possess unique properties such as biocompatibility, tunable pore size, high surface area, and ease of modification. For this reason, Si-NPs have been widely used in gene transfection, drug delivery, biosensing and bioimaging [164-166]. It has been observed that these nanostructures promote osteoblast differentiation through autophagy stimulation [167]. Si-NPs have also been shown to stimulate ROS generation, oxidative stress and ER stress that lead to autophagy activation via unfolded protein response (UPR) pathways in hepatocytes [168].

Several other studies reported that through autophagy modulation, Si-NPs exert cytotoxic effect in cancer cells thus highlighting their potential therapeutic effect. It has been reported that Si-NPs can lead to apoptosis, mitophagy, autophagy, and consequently ROS accumulation in glioblastoma LBC3 cells representing a potential therapeutic agent for glioblastoma multiforme therapy [169].

Intriguingly, it has been shown that accumulation of Si-NPs in human cervix carcinoma cells may lead to lysosomal dysfunctions and autophagy defects, resulting in a reduced metabolic activity of cancer cells [170]. Recently, genistein-PEGylated silica hybrid nanomaterials (Gen-PEG-SiHNM) have been developed, which possess antiproliferative effects by activating apoptosis and autophagy cell death in HT29 human colon cancer cells [171]. This study suggests that Gen-PEG-SiHNM may be potentially used as an alternative treatment for colorectal cancer in the near future.

Si-NPs have also been observed to induce ROS and autophagy dysfunction in HCT-116 colon cancer cells, L-02 and HepG2 hepatoma cells, providing novel evidence for the study of toxic effect and safety evaluation of Si-NPs [117, 172-174]. Endoplasmic reticulum-involved autophagic process (ER autophagy) is a selective form of autophagy in which these organelles can be captured by autophagy process if they are damaged $[175,176]$. Recently, it has been observed that Si-NPs induce endoplasmic reticulum (ER) autophagy in HCT-116 human colon cancer cells without exhibiting a strong cytotoxic effect. The autophagy induced by these nanomaterials was detected by the increase of LC3-II and was associated with the treated time but not by the concentration used. These new findings of Si-NPs-induced ER autophagy could open an effective way for securely designing silica-based nanoparticles and could potentially represent a valid therapeutic tool in autophagy-linked diseases [174] (Table 2). 


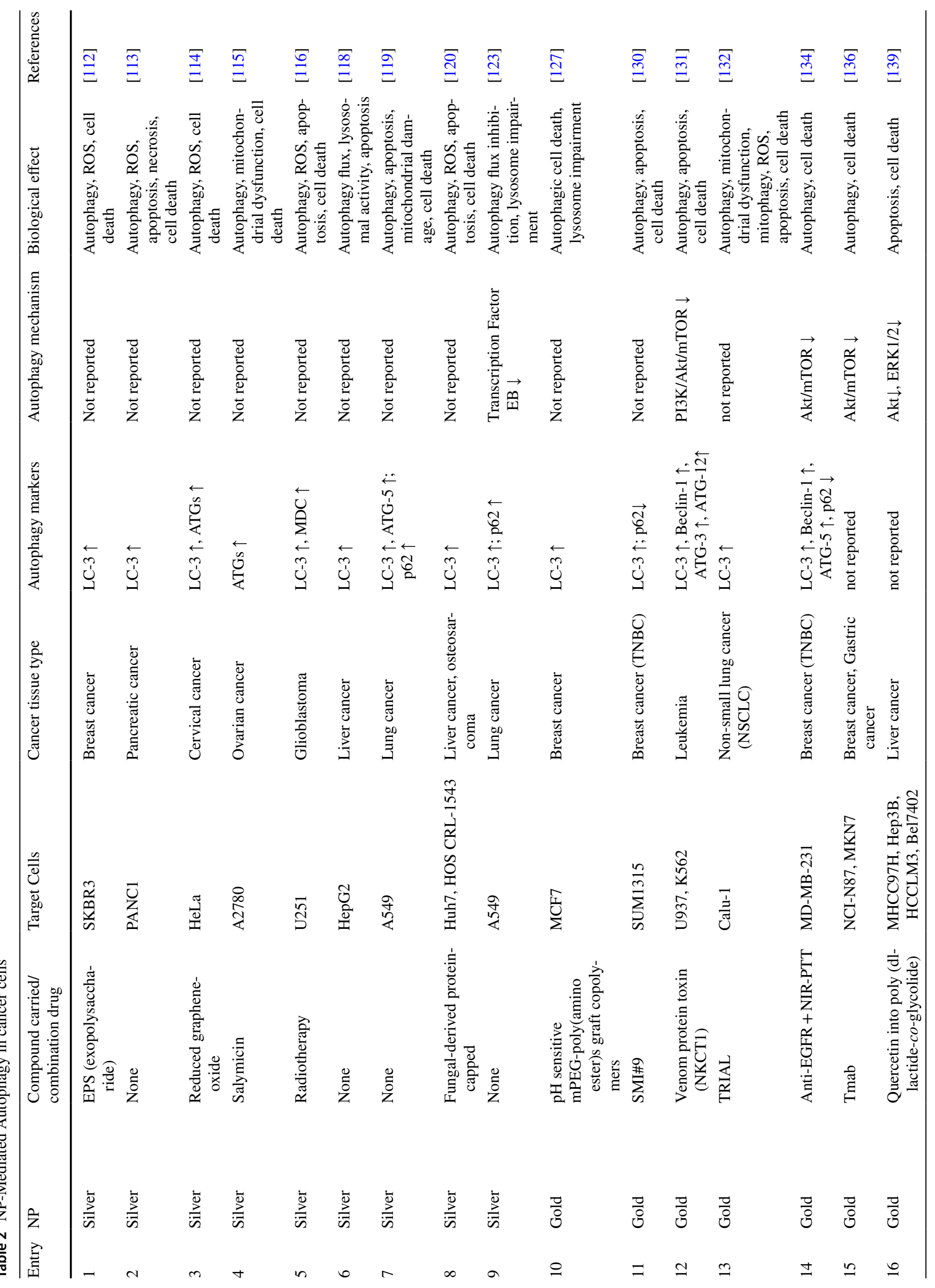




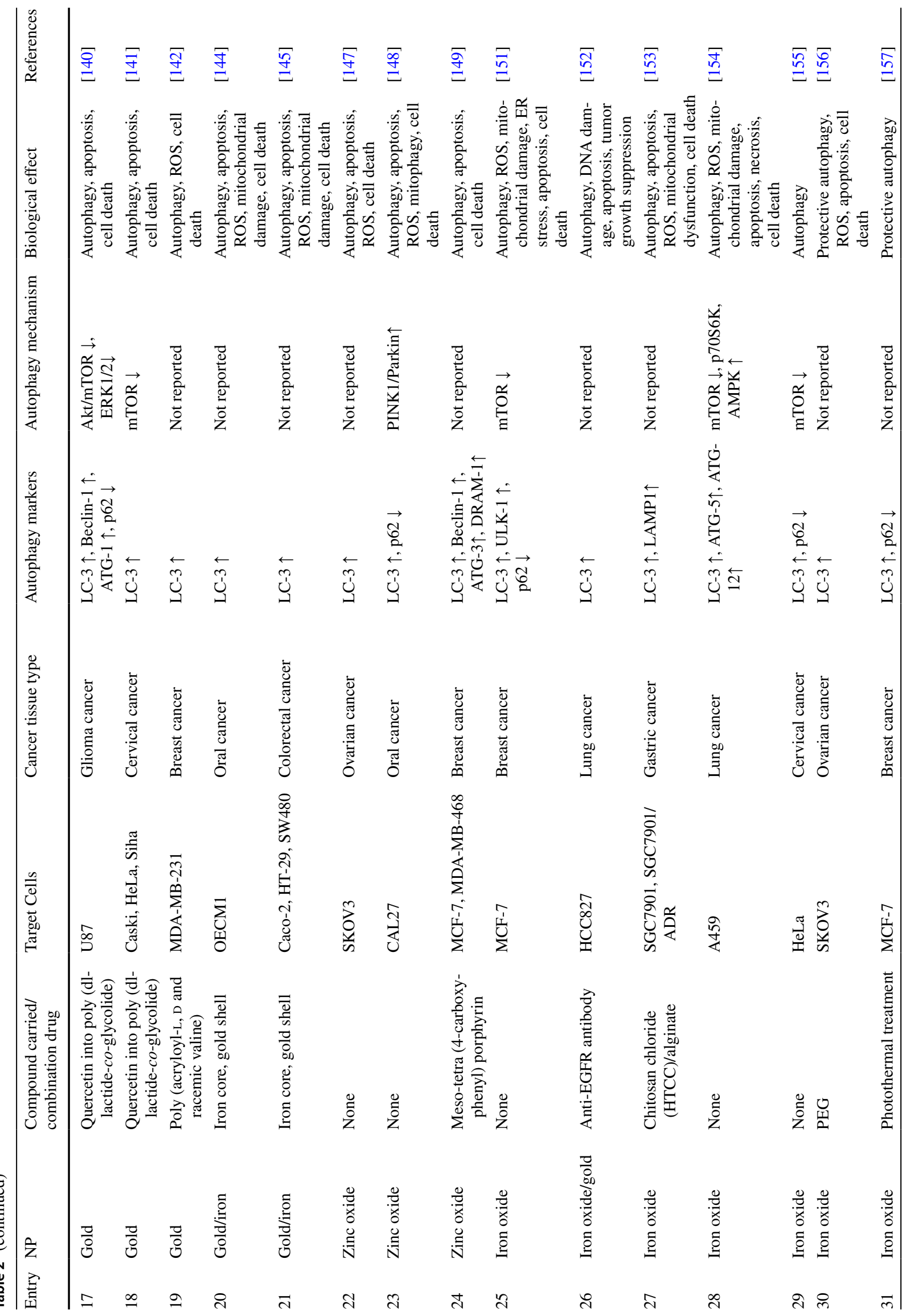




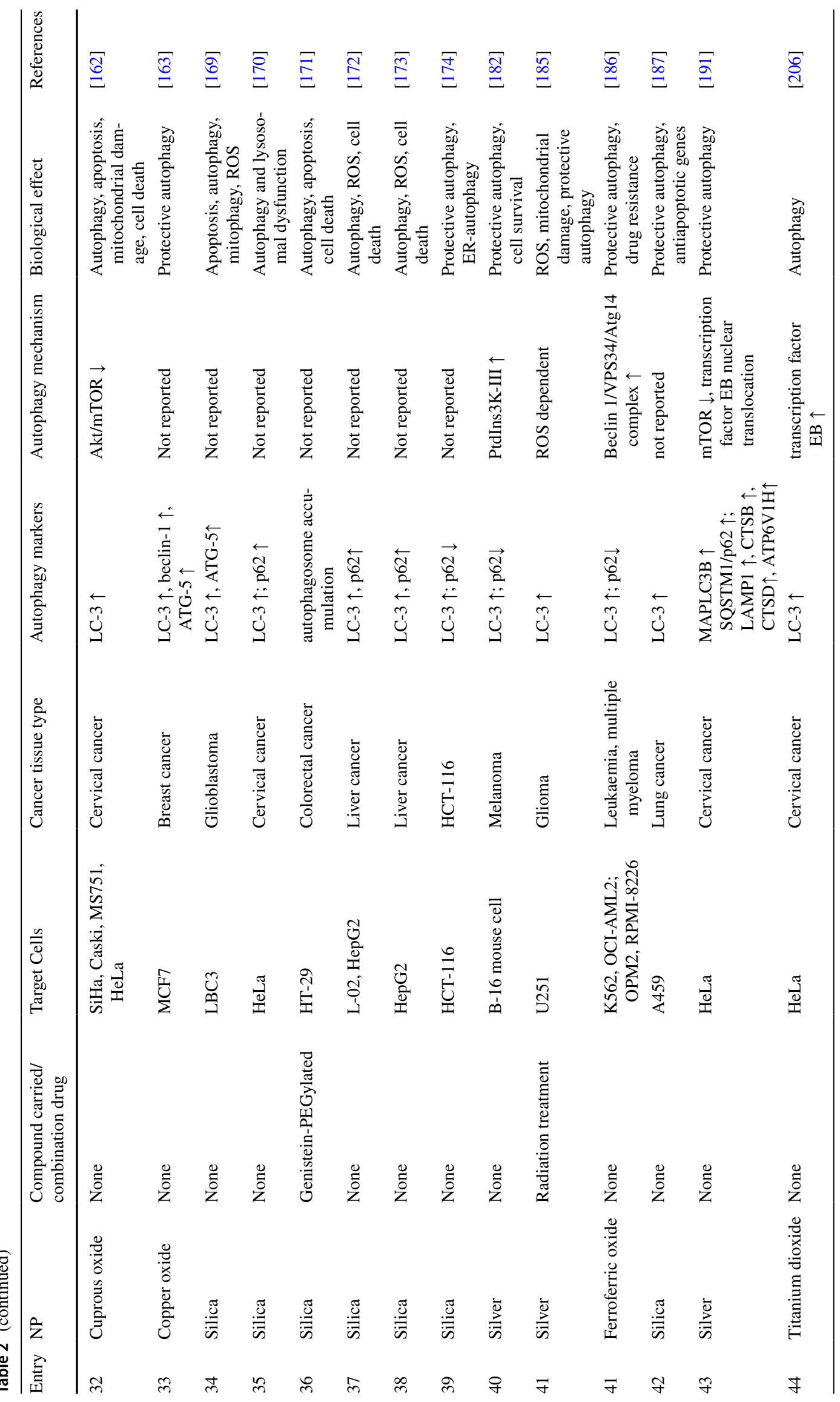




\section{Other examples of autophagy modulation using nanoparticles}

The use of nanoparticles to modulate autophagy is not just limited to cancer, and a variety of maladies can be treated by this approach, such as muscular or neurodegenerative diseases. Neurodegenerative diseases are a complex set of severe disorders characterized by the progressive loss of neurons leading to severe physical and cognitive inabilities in affected patients. Impairment of autophagy machinery has been reported to be linked with the development of these diseases, and several studies have recently reported that autophagy modulation by nanoparticles may represent a valid therapeutic opportunity.

Cerium oxide nanoparticles $\left(\mathrm{CeO}_{2}\right.$-NPs), due to their antioxidant proprieties, have been exploited for biomedical application [177, 178]. In addition to protect cells from oxidative stress, these nanomaterials were reported to activate autophagy and promote clearance of autophagic cargo, thus exerting a neuroprotective function. Interestingly, different functionalized $\mathrm{CeO}_{2}$-NPs have been shown to enhance autophagic clearance of proteolipid aggregates in fibroblasts derived from a patient with late infantile neuronal ceroid lipofuscinosis (LINCL) that accumulates the autophagic substrate ceroid lipopigment as a result of the inefficient function of the lysosome autophagy system. At the mechanistic level, autophagy induction by $\mathrm{CeO}_{2}$-NPs was due to the activation of TFEB that controls the expression of genes involved in lysosomal function and autophagy [179].

Europium hydroxide nanoparticles [(EuIII $\left.\left.(\mathrm{OH})_{3}\right)-\mathrm{NPs}\right]$ has been shown to be able to reduce mutant huntingtin protein aggregation via autophagy induction, which is responsible for many neurodegenerative diseases. The induction of autophagy flux by [(EuIII $(\mathrm{OH}) 3)-\mathrm{NPs}]$ has been observed in different cell lines such as Neuro 2a, PC12 and HeLa cells, and it was due to the expression of characteristic autophagy marker LC3-II and degradation of selective autophagy substrate/cargo receptor p62/SQSTM1 [180] (Table 3).

As occurs for neurodegenerative diseases, also skeletal muscles are often characterized by impaired autophagy clearance and display accumulation of damaged organelles, or misfolded proteins, inside myofibers. Recently, it has been observed that rapamycin-loaded nanoparticles can rescue a correct autophagy flux in $m d x$ mice, a model of Duchenne muscular dystrophy, thus increasing skeletal muscle strength that cannot be achieved with pharmacological doses of conventional oral rapamycin. Therefore, rapamycin-loaded nanoparticles could represent an attractive therapeutic alternative by inducing an autophagy clearance in dystrophic muscles [181] (Table 4).

Elevation of autophagy level is a common response of cells upon exposure to metallic nanomaterials, and we have summarized the recent studies reporting that a great variety of these nanostructures may induce autophagy cell death in cancer cells. Paradoxically, in some cases it has been reported that metallic nanoparticles may have opposing roles on the cell fate. Emerging evidence indicates that some metallic nanomaterials induce prosurvival autophagy in both cancer and normal cells [120, 156, 182-188]. For example, ferroferric oxide nanoparticles have been shown to induce pro-survival autophagy in human blood cells by modulating the Beclin1/Bcl-2/ VPS34 complex [186]. Recently, it has also been reported that lactosylated $\mathrm{N}$-alkyl polyethylenimine-coated iron oxide nanoparticles induce protective autophagy in mouse dendritic cells [189]. Bismuth nanoparticles (Bi-NPs) induce protective autophagy in human embryonic kidney cells 293 through the regulation of AMPK/mTOR signal pathway [190]. It has also been published that Ag-NPs induce protective autophagy in HeLa cells by evoking the nuclear translocation of TFEB and consequently the transcription of autophagy and lysosomal-related genes [191].

In all these circumstances, inhibition of autophagy becomes a viable approach for enhancing cancer therapeutic efficacy. However, why some metallic nanomaterials induce pro-death autophagy, while others elicit pro-survival autophagy is poorly understood, and the molecular mechanism underlying these two drastically different effects is largely unexplored.

\section{Nanotoxicology}

Despite the therapeutic advantages of nanomaterials, it is necessary to remind that these products can present some toxicity. Interestingly, the toxicity and the therapeutic effect observed might be derived from the modulation of the autophagy. For instance, Si-NPs have been shown to induce cytotoxicity and autophagy cell death on human umbilical vein, cerebral and corneal endothelial cells through several mechanisms, including ROS generation, dysregulation of $\mathrm{PI} 3 \mathrm{~K} / \mathrm{Akt} / \mathrm{mTOR}$ pathway, by affecting angiogenesis and cellular homeostasis, and by leading mitochondrial instability and mitophagy [192-196]. Si-NPs, depending on their size, have also been shown to induce cytotoxicity and autophagy dysfunction in human bronchial epithelial BEAS2B cells [197]. This occurred through the upregulation of autophagy markers LC3 and p62, and by modulating PI3K/ Akt/mTOR pathway in size- and dose-dependent manner [197]. This study shows that Si-NPs could lead autophagy dysfunction and impairment of cellular homeostasis in the respiratory system. Moreover, it has been observed that $\mathrm{Si}$ NPs also may induce autophagy and cell death in neuronal PC12 cells [198]. The autophagy induction, together with ROS increase, and inhibition of ubiquitin-proteasome system (UPS), results in the aggregation of mutant $\alpha$-synuclein, 


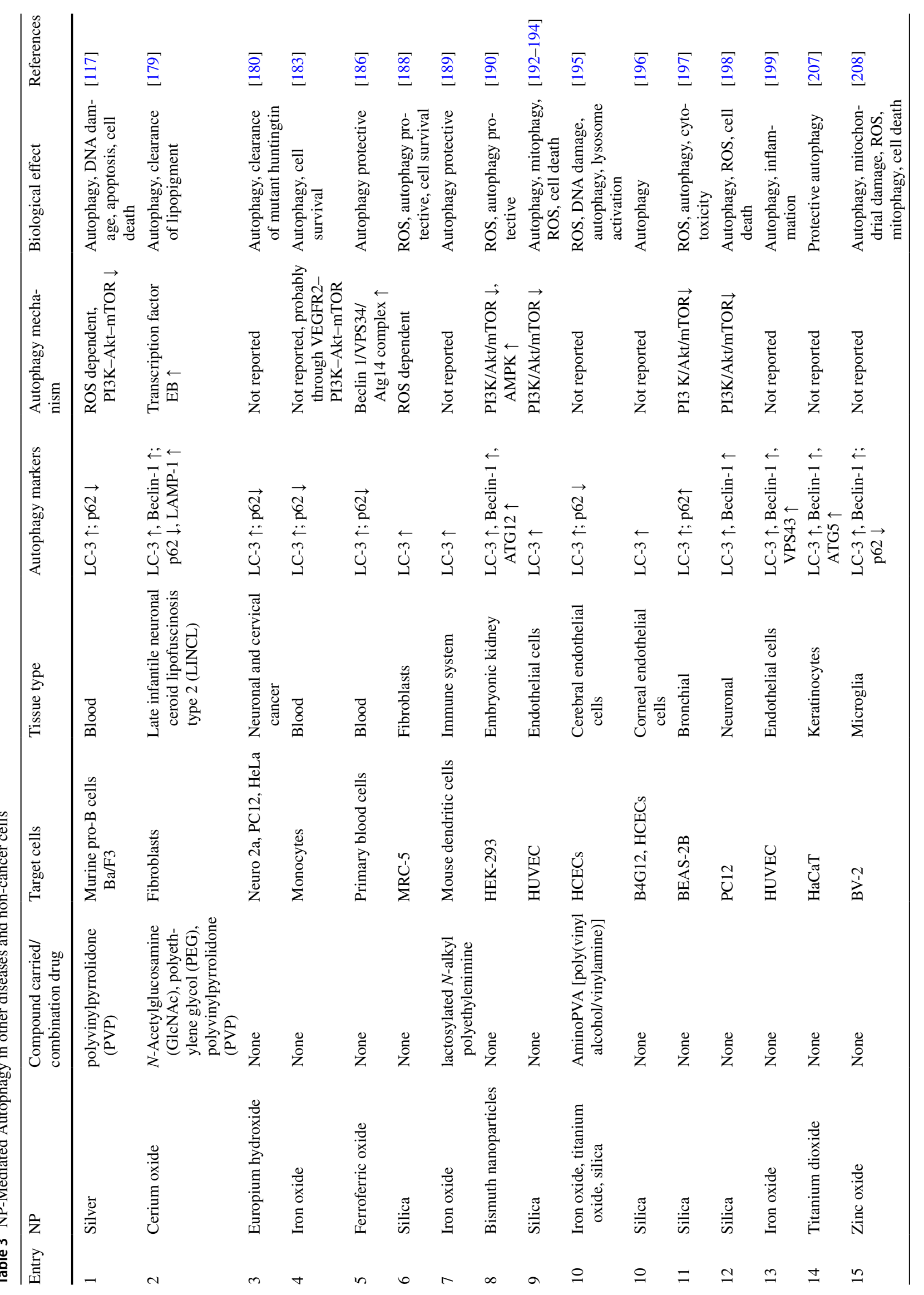




\begin{tabular}{|c|c|c|c|c|c|c|c|}
\hline 岕 & 灾 & $\stackrel{\bar{\Xi}}{\mathrm{d}}$ & $\overline{\widetilde{a}}$ & $\stackrel{\bar{a}}{\underline{d}}$ & 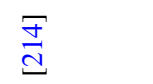 & & $\stackrel{\square}{d}$ \\
\hline 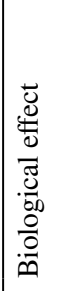 & 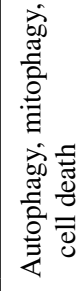 & 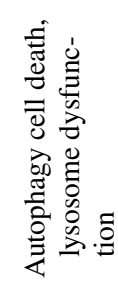 & 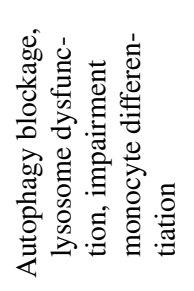 & 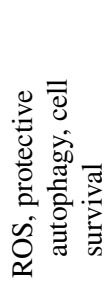 & 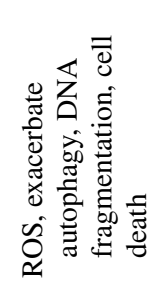 & 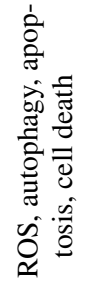 & 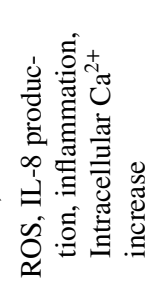 \\
\hline 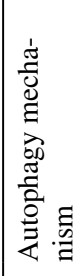 & 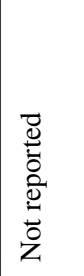 & 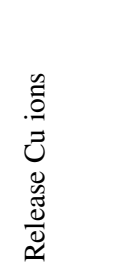 & 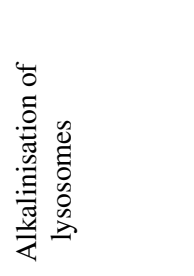 & 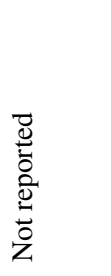 & 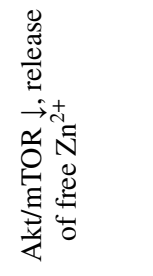 & 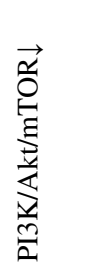 & 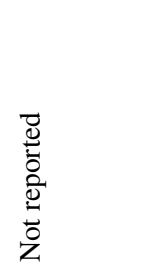 \\
\hline 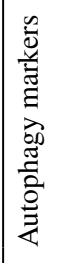 & $\overleftrightarrow{\overbrace{}}$ & 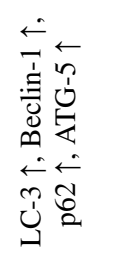 & 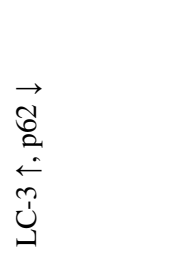 & 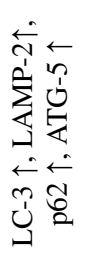 & 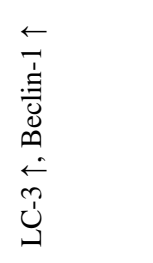 & 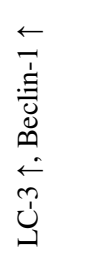 & 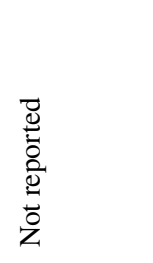 \\
\hline 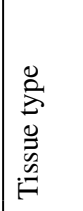 & $\begin{array}{l}\bar{\Xi} \\
\overline{0} \\
\bar{\Xi} \\
\bar{Z}\end{array}$ & 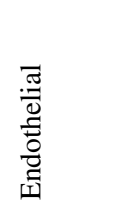 & 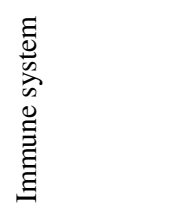 & 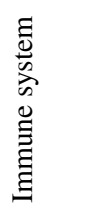 & 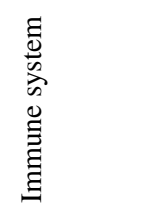 & 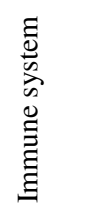 & 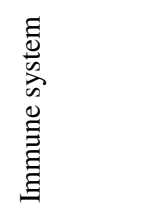 \\
\hline 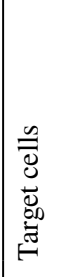 & $\begin{array}{l}\tilde{z} \\
\dot{z} \\
\approx \\
\approx\end{array}$ & 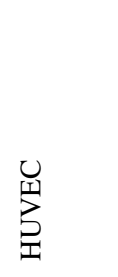 & 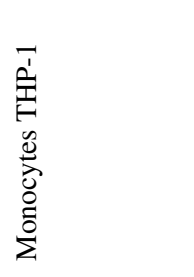 & 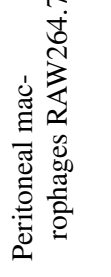 & 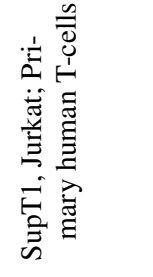 & 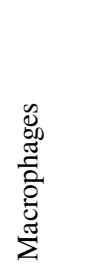 & 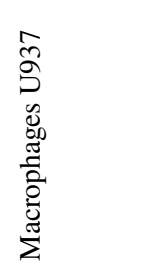 \\
\hline 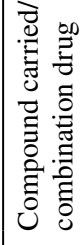 & 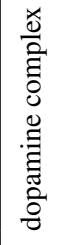 & $\begin{array}{l}0 \\
\tilde{z}\end{array}$ & $\begin{array}{l}\text { हूँ } \\
\text { Zे }\end{array}$ & $\begin{array}{l}\text { ̊̆ } \\
\text { ż }\end{array}$ & ż & 艺 & 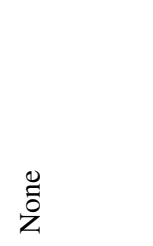 \\
\hline Z & 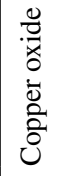 & 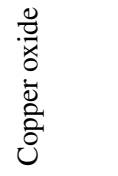 & 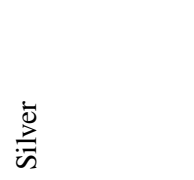 & 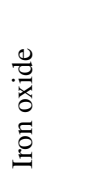 & 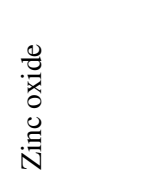 & 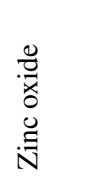 & 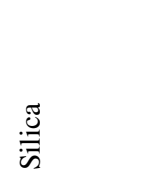 \\
\hline 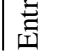 & $\stackrel{0}{0}$ & $=$ & $\Xi$ & $\stackrel{\infty}{\sim}$ & 2 & ‡ి & $\vec{\sim}$ \\
\hline
\end{tabular}


Table 4 In vivo assays performed in the studies reported in the review

\begin{tabular}{|c|c|c|c|c|c|c|}
\hline Entry & NP & $\begin{array}{l}\text { Compound carried/com- } \\
\text { bination drug }\end{array}$ & Mouse model & Disease model & Biological effect & References \\
\hline 1 & Silver & Radiotherapy & Orthotopic mouse & Brain cancer & $\begin{array}{l}\text { Enhancement in mean } \\
\text { survival time, increas- } \\
\text { ing cure rate in glioma- } \\
\text { bearing rats }\end{array}$ & [116] \\
\hline 2 & Gold & TRAIL & $\begin{array}{l}\text { Nude mice bearing } \\
\text { Calu- } 1 \text { cells }\end{array}$ & $\begin{array}{l}\text { non-small-cell lung } \\
\text { cancer (NSCLC) }\end{array}$ & Reduction tumor growth & [132] \\
\hline 3 & Gold & Tmab & $\begin{array}{l}\text { Subcutaneous mouse } \\
\text { NCI-N87, MKN7 }\end{array}$ & Breast cancer & $\begin{array}{l}\text { Growth suppression, } \\
\text { autophagy induction }\end{array}$ & [136] \\
\hline 4 & Gold & Quercetin & $\begin{array}{l}\text { Old male BALB/c nu/nu } \\
\text { nude mice xenograft } \\
\text { models }\end{array}$ & Glioblastoma & $\begin{array}{l}\text { Inhibition of tumor } \\
\text { growth, low toxicity, } \\
\text { improved survival in } \\
\text { mice }\end{array}$ & {$[140]$} \\
\hline 5 & Gold & Quercetin & $\begin{array}{l}\text { Old male BALB/c nu/nu } \\
\text { nude mice xenograft } \\
\text { models }\end{array}$ & Cervical cancer & $\begin{array}{l}\text { Apoptosis, inhibition } \\
\text { cancer growth, and } \\
\text { progression }\end{array}$ & [141] \\
\hline 6 & Gold & $\begin{array}{l}\text { Poly (acryloyl-L, D and } \\
\text { racemic valine) }\end{array}$ & $\begin{array}{l}\text { BALB/C mice and nude } \\
\text { mice }\end{array}$ & Breast cancer & $\begin{array}{l}\text { Autophagy, reduction } \\
\text { tumor growth }\end{array}$ & [142] \\
\hline 7 & Iron oxide/gold & Anti-EGFR antibody & Old female nude mice & Lung Cancer & $\begin{array}{l}\text { Autophagy, DNA dam- } \\
\text { age, apoptosis, tumor } \\
\text { growth suppression }\end{array}$ & [152] \\
\hline 8 & Iron oxide & $\begin{array}{l}\text { Chitosan chloride } \\
\text { (HTCC)/alginate }\end{array}$ & $\begin{array}{l}\text { Gastric SGC7901/ADR- } \\
\text { fluc tumor-bearing mice }\end{array}$ & Gastric cancer & $\begin{array}{l}\text { Cytotoxicity, autophagy, } \\
\text { apoptosis }\end{array}$ & [153] \\
\hline 9 & Iron oxide & $\begin{array}{l}\text { Photothermal treatment, } \\
\text { CQ }\end{array}$ & $\begin{array}{l}\text { Mude mice bearing } \\
\text { MCF-7 xenograft }\end{array}$ & Breast cancer & $\begin{array}{l}\text { Tumor inhibition, } \\
\text { autophagosomes accu- } \\
\text { mulation, apoptosis }\end{array}$ & [157] \\
\hline 10 & Cuprous oxide & None & $\begin{array}{l}\text { Cervical carcinoma } \\
\text { xenograft in nude mice }\end{array}$ & Cervical cancer & $\begin{array}{l}\text { Suppression tumor } \\
\text { growth }\end{array}$ & {$[162]$} \\
\hline 11 & Rapamycin & None & $\begin{array}{l}\text { C57BL10 mice, } \\
\text { C57BL/10ScSn- } \\
\text { Dmdmdx/J mice }\end{array}$ & $\begin{array}{l}\text { Duchenne muscular } \\
\text { dystrophy }\end{array}$ & $\begin{array}{l}\text { Autophagy, recovery } \\
\text { of skeletal muscle } \\
\text { strength }\end{array}$ & [181] \\
\hline 12 & Silver & None & Male C57BL & Melanoma & $\begin{array}{l}\text { Strong cell growth } \\
\text { inhibition in combina- } \\
\text { tion with autophagy } \\
\text { inhibitor }\end{array}$ & [182] \\
\hline 13 & Silver & None & $\begin{array}{l}\text { Adult male Sprague- } \\
\text { Dawley rats }\end{array}$ & Liver toxicity & $\begin{array}{l}\text { Oxidative stress, mark- } \\
\text { ers, hepatotoxicity, } \\
\text { protective autophagy }\end{array}$ & [184] \\
\hline 14 & Silica & None & $\begin{array}{l}\text { New Zealand white } \\
\text { rabbits }\end{array}$ & Ocular toxicity & $\begin{array}{l}\text { Autophagy, no toxicity } \\
\text { reported }\end{array}$ & [196] \\
\hline
\end{tabular}

thus representing a significant risk factor for the development of Parkinson disease [198]. In addition, high concentrations of magnetic iron oxide nanoparticles $\left(\mathrm{Fe}_{3} \mathrm{O}_{4}\right.$-NPs) have been reported to lead endothelial dysfunction, inflammation and cardiovascular diseases, through both autophagy induction and the blockade of autophagy flux in HUVECs [199]. Titanium dioxide nanoparticles $\left(\mathrm{TiO}_{2}-\mathrm{NPs}\right)$ are semiconductor nanomaterials that have been explored for drug delivery purposes and are attracting an increasing level of attention [200, 201]. However, although this nanomaterial has been largely studied for their potent cytotoxic effect in a variety of cancer cells [202-206], it may induce autophagy response in HaCaT human keratinocyte cells [207]. A recent report showed that ZnO-NPs significantly increased the autophagy, ROS level and mitochondrial impairment in BV-2 microglia cell line, in a time-dependent manner. In addition to changes in autophagy markers, a PINK1/parkin-mediated mitophagy has also been reported. The data reported by the authors suggested that mitophagy could play a protective role in $\mathrm{ZnO}$ NP-induced toxicity in BV-2 cells [208]. Despite the therapeutic potential of CO-NPs in a variety of cancer cell lines, a specific neurotoxic action of a copper-dopamine complex in neuronal RCSN-3 cells has also been reported. This occurs by inducing mitochondrial autophagy followed by caspase-3-independent apoptotic cell death [209]. CO-NPs also trigger HUVEC cell death via autophagy and lysosomal 
dysfunction [210]. It has been reported that polyvinylpyrrolidone (PVP)-coated Ag-NPs have an anti-leukemia effect against human myeloid leukemia cells [182, 185]. However, Ag-NPs have also been shown to trigger cytotoxic autophagy in non-cancer murine pro- $\mathrm{B}$ cells $(\mathrm{Ba} / \mathrm{F} 3)$ through the modulation of PI3K/mTOR signaling pathway along with generation of ROS and release of silver ions [117]. Interestingly, some studies report that metallic nanomaterials possess intrinsic toxicity versus immune system components by modulating autophagy. Among the plethora of cells that constitute the immune system, macrophages mediate innate immune responses and contribute to adaptive immunity via antigen processing [211]. It has been reported that $\mathrm{Ag}$ NPs impair monocyte-macrophage differentiation through autophagy blockade, which is mediated by lysosomal dysfunction. Indeed, lysosomal impairment was observed in Ag-NP-treated THP-1 cells, which is responsible for the blockade of autophagic flux [212]. This study suggests a crosstalk among monocyte differentiation, autophagy, and lysosomal dysfunction simultaneously induced by Ag-NPs. In addition, $\mathrm{Fe}_{3} \mathrm{O}_{4}$-NPs have been reported to induce prosurvival autophagy in RAW264.7 cells derived from mouse peritoneal macrophages. The induction of autophagy markers and ROS levels after treatment with $\mathrm{Fe}_{3} \mathrm{O}_{4}$-NPs were accompanied by the ERK pathway that was activated for cell survival [213]. Interestingly, it has been reported that acute exposure to $\mathrm{ZnO}$-NPs induces autophagic immune cell death. This occurs by the release of free $\mathrm{Zn}(2+)$ that can be taken up by immune cells triggering the production of excessive intracellular ROS that leads to exacerbated autophagy [214, 215]. Many other studies reported that SiNPs possess strong toxicity against immune components through the enhancement of proinflammatory responses, oxidative stress and autophagy modulation [216, 217]. These and other studies (reviewed in Peynshaert, 2014) indicate that autophagy modulation mediated by inorganic NPs can potentially represent a risk for immune system, cardiovascular and neurological health. However, the involvement and nature of autophagy deregulation in the pathogenesis of the above-described diseases need further investigation before making conclusions regarding the real cardiovascular and neurological dangers of these nanomaterials and to eventually efficiently target autophagy as a therapeutic strategy.

\section{Conclusion and future perspective}

Human tumors are complex diseases resulting from the interplay between genetic and environmental factors. Besides the many cellular and genetic alterations, cancer cells share common features responsible for their phenotypic manifestations, including uncontrolled proliferation and growth, dysregulation of apoptosis and insensitivity, and severe metabolic alterations [2]. Autophagy is a tightly regulated cellular degradative process by which damaged macromolecules and organelles are targeted by autophagic vesicles to lysosomes and then eliminated [218]. Autophagy is frequently dysregulated in tumors, however, its role in regulating cancer cell death or survival remains highly debated and dependent on metabolic context and on the microenvironmental conditions of the cells [219]. Some studies suggest that basal autophagy may have a protective role in cancer by providing the nutrients necessary for their uncontrolled growth as well as favoring cancer cell survival in many hypoxic tumor microenvironments [48]. However, it is also well assumed that overstimulating autophagy machinery can also lead to cell death, also called cell death-type II, likely due to excessive degradation of cellular constituents and organelles required for homeostasis of the cells [46]. There is mounting evidence that targeting autophagy may be employed as a therapeutic strategy itself or may enhance the efficacy of anticancer therapies [71,220]. The field of nanotechnology is greatly expanding and can provide the necessary tools to overcome the limits frequently observed with traditional treatments.

This review presents an overview of the most recent reports on NP-mediated autophagy alterations and their impact on nanomedicine. Many studies have shown that nanomaterials and particularly metallic nanoparticles can be used to treat cancer by modulating autophagy. These nanostructures may also promote a plethora of events such as mitochondrial damage, lysosome impairment, ER stress and alterations of signaling pathways, which results in the activation of mitophagy, oxidative stress, and autophagic cell death. Importantly, these materials have shown intrinsic selectivity in inducing autophagy in cancer cells compared to noncancerous cells. However, metal-based nanomaterials may have opposing roles on cell fate being able to induce pro-survival autophagy in cancer and normal cells [162, 184-189]. Thus, inhibition of autophagy may be a viable approach for enhancing cancer therapeutic efficacy.

Autophagy induced by nanomaterials can also be used to treat other diseases such as muscular and neurodegenerative disorders. It is due to their ability to restore a proper autophagic flux, thus removing the protein aggregates and damaged organelles, responsible for the pathogenesis of these diseases [64, 68].

Hence, the capability of many nanostructures to overstimulate autophagy may acquire exceptional medical and toxicological importance. However, more research is needed to define the mechanisms underlying the NP-induced autophagy modulation.

In conclusion, the findings summarized in this review suggest that autophagy modulation with nanoparticle-based strategies would acquire clinical relevance in the near future, 
as complementary therapies for the treatment of cancers and other diseases.

Acknowledgements This work was partially supported by the Spanish Ministry of Economy and Competitiveness (SAF2017-87305-R), Comunidad de Madrid (IND2017/IND-7809; S2017/BMD-3867), co-financed by European Structural and Investment Fund, Asociación Española Contra el Cáncer (Singulares 2014), the European Union's Horizon 2020 research and innovation programme under Grant agreement no 685795 and IMDEA Nanociencia. IMDEA Nanociencia acknowledges support from the 'Severo Ochoa' Programme for Centres of Excellence in R\&D (MINECO, Grant SEV-2016-0686).

Open Access This article is distributed under the terms of the Creative Commons Attribution 4.0 International License (http://creativeco mmons.org/licenses/by/4.0/), which permits unrestricted use, distribution, and reproduction in any medium, provided you give appropriate credit to the original author(s) and the source, provide a link to the Creative Commons license, and indicate if changes were made.

\section{References}

1. Stewart BW, Wild CP (2014) World cancer report 2014, World Health Organisation. ISBN-13 978-92-832-0429-9

2. Hanahan D, Weinberg RA (2000) The hallmarks of cancer. Cancer Immunol Immunother 60(2011):319-326. https://doi. org/10.1007/s00262-010-0968-0

3. Liang XH, Jackson S, Seaman M, Brown K, Kempkes B, Hibshoosh H, Levine B (1999) Induction of autophagy and inhibition of tumorigenesis by beclin 1. Nature 402:672-676. https://doi. org/10.1038/45257

4. Mathew R, Karantza-Wadsworth V, White E (2007) Role of autophagy in cancer. Nat Rev Cancer 7:961-967

5. Amaravadi RK, Yu D, Lum JJ, Bui T, Christophorou MA, Evan GI, Thomas-Tikhonenko A, Thompson CB (2007) Autophagy inhibition enhances therapy-induced apoptosis in a Myc-induced model of lymphoma. J Clin Investig 117:326-336. https://doi. org/10.1172/JCI28833

6. Sinha R (2006) Nanotechnology in cancer therapeutics: bioconjugated nanoparticles for drug delivery. Mol Cancer Ther 5:1909-1917. https://doi.org/10.1158/1535-7163.MCT-06-0141

7. Wicki A, Witzigmann D, Balasubramanian V, Huwyler J (2015) Nanomedicine in cancer therapy: challenges, opportunities, and clinical applications. J Control Release 200:138-157. https://doi. org/10.1016/j.jconrel.2014.12.030

8. Pouponneau P, Leroux JC, Soulez G, Gaboury L, Martel S (2011) Co-encapsulation of magnetic nanoparticles and doxorubicin into biodegradable microcarriers for deep tissue targeting by vascular MRI navigation. Biomaterials 32:3481-3486. https://doi. org/10.1016/j.biomaterials.2010.12.059

9. Abbaszad Rafi A, Mahkam M, Davaran S, Hamishehkar H (2016) A smart $\mathrm{pH}$-responsive nano-carrier as a drug delivery system: a hybrid system comprised of mesoporous nanosilica MCM41 (as a nano-container) \& a pH-sensitive polymer (as smart reversible gatekeepers): preparation, characterization and in vitro release st. Eur J Pharm Sci 93:64-73. https://doi.org/10.1016/j. ejps.2016.08.005

10. Tran S, DeGiovanni P-J, Piel B, Rai P (2017) Cancer nanomedicine: a review of recent success in drug delivery. Clin Transl Med 6:44. https://doi.org/10.1186/s40169-017-0175-0

11. Aftab S, Shah A, Nadhman A, Kurbanoglu S, Aysil Ozkan S, Dionysiou DD, Shukla SS, Aminabhavi TM (2018) Nanomedicine: an effective tool in cancer therapy. Int J Pharm 540:132-149. https://doi.org/10.1016/j.ijpharm.2018.02.007

12. Bobo D, Robinson KJ, Islam J, Thurecht KJ, Corrie SR (2016) Nanoparticle-based medicines: a review of FDA-approved materials and clinical trials to date. Pharm Res 33:2373-2387. https ://doi.org/10.1007/s11095-016-1958-5

13. Wang YC, Wang F, Sun TM, Wang J (2011) Redox-responsive nanoparticles from the single disulfide bond-bridged block copolymer as drug carriers for overcoming multidrug resistance in cancer cells. Bioconj Chem 22:1939-1945. https://doi. org $/ 10.1021 / \mathrm{bc} 200139 \mathrm{n}$

14. Panzarini E, Dini L (2014) Nanomaterial-induced autophagy: a new reversal MDR tool in cancer therapy? Mol Pharm 11:25272538. https://doi.org/10.1021/mp500066v

15. Peynshaert K, Manshian BB, Joris F, Braeckmans K, De Smedt SC, Demeester J, Soenen SJ (2014) Exploiting intrinsic nanoparticle toxicity: the pros and cons of nanoparticle-induced autophagy in biomedical research. Chem Rev 114:7581-7609. https://doi.org/10.1021/cr400372p

16. Mizushima N (2009) Physiological functions of autophagy. Curr Top Microbiol Immunol 335:71-84. https://doi.org/10.1007/9783-642-00302-8-3

17. Mizushima N (2007) Autophagy: process and function. Genes Dev 21:2861-2873. https://doi.org/10.1101/gad.1599207

18. Pattingre S, Espert L, Biard-Piechaczyk M, Codogno P (2008) Regulation of macroautophagy by mTOR and Beclin $1 \mathrm{com}-$ plexes. Biochimie 90:313-323. https://doi.org/10.1016/j.bioch i. 2007.08 .014

19. Backer JM (2008) The regulation and function of Class III PI3Ks: novel roles for Vps34. Biochem J 410:1-17. https://doi. org/10.1042/BJ20071427

20. Øvervatn A, Bjørkøy G, Johansen T (2007) p62/SQSTM1 binds directly to Atg8/LC3 to facilitate degradation of ubiquitinated protein aggregates. J Biol Chem 282:24131-24145. https://doi. org/10.1074/jbc.M702824200

21. Kirkin V, McEwan DG, Novak I, Dikic I (2009) A role for ubiquitin in selective autophagy. Mol Cell 34:259-269. https://doi. org/10.1016/j.molcel.2009.04.026

22. Gwinn DM, Shackelford DB, Egan DF, Mihaylova MM, Mery A, Vasquez DS, Turk BE, Shaw RJ (2008) AMPK phosphorylation of raptor mediates a metabolic checkpoint. Mol Cell 30:214-226. https://doi.org/10.1016/j.molcel.2008.03.003

23. Inoki K, Ouyang H, Zhu T, Lindvall C, Wang Y, Zhang X, Yang Q, Bennett C, Harada Y, Stankunas K, yu Wang C, He X, MacDougald OA, You M, Williams BO, Guan KL (2006) TSC2 integrates Wnt and energy signals via a coordinated phosphorylation by AMPK and GSK3 to regulate cell growth. Cell 126:955-968. https://doi.org/10.1016/j.cell.2006.06.055

24. Kim J, Kundu M, Viollet B, Guan KL (2011) AMPK and mTOR regulate autophagy through direct phosphorylation of Ulk1. Nat Cell Biol 13:132-141. https://doi.org/10.1038/ncb2152

25. Noda T, Ohsumi Y (1998) Tor, a phosphatidylinositol kinase homologue, controls autophagy in yeast. J Biol Chem 273:39633966. https://doi.org/10.1074/jbc.273.7.3963

26. Wullschleger S, Loewith R, Hall MN (2006) TOR signaling in growth and metabolism. Cell 124:471-484. https://doi. org/10.1016/j.cell.2006.01.016

27. Arias E, Koga H, Diaz A, Mocholi E, Patel B, Cuervo AM (2015) Lysosomal mTORC2/PHLPP1/Akt regulate chaperone-mediated autophagy. Mol Cell 59:270-284. https://doi.org/10.1016/j.molce 1.2015.05.030

28. Mammucari C, Milan G, Romanello V, Masiero E, Rudolf R, Del Piccolo P, Burden SJ, Di Lisi R, Sandri C, Zhao J, Goldberg AL, Schiaffino S, Sandri M (2007) FoxO3 controls autophagy in skeletal muscle in vivo. Cell Metab 6:458-471. https://doi. org/10.1016/j.cmet.2007.11.001 
29. Mizushima N (2010) The role of the Atg1/ULK1 complex in autophagy regulation. Curr Opin Cell Biol 22:132-139. https:// doi.org/10.1016/j.ceb.2009.12.004

30. Crighton D, Wilkinson S, Ryan KM (2007) DRAM links autophagy to 553 and programmed cell death. Autophagy 3:7274. https://doi.org/10.4161/auto.3438

31. Jones RG, Plas DR, Kubek S, Buzzai M, Mu J, Xu Y, Birnbaum MJ, Thompson CB (2005) AMP-activated protein kinase induces a p53-dependent metabolic checkpoint. Mol Cell 18:283-293. https://doi.org/10.1016/j.molcel.2005.03.027

32. Okoshi R, Ozaki T, Yamamoto H, Ando K, Koida N, Ono S, Koda T, Kamijo T, Nakagawara A, Kizaki H (2008) Activation of AMP-activated protein kinase induces p53-dependent apoptotic cell death in response to energetic stress. J Biol Chem 283:39793987. https://doi.org/10.1074/jbc.M705232200

33. He G, Zhang Y-W, Lee J-H, Zeng SX, Wang YV, Luo Z, Dong XC, Viollet B, Wahl GM, Lu H (2014) AMP-activated protein kinase induces p53 by phosphorylating MDMX and inhibiting its activity. Mol Cell Biol 34:148-157. https://doi.org/10.1128/ MCB.00670-13

34. Feng Z, Hu W, De Stanchina E, Teresky AK, Jin S, Lowe S, Levine AJ (2007) The regulation of AMPK $\beta 1$, TSC2, and PTEN expression by p53: stress, cell and tissue specificity, and the role of these gene products in modulating the IGF-1AKT-mTOR pathways. Cancer Res 67:3043-3053. https://doi. org/10.1158/0008-5472.CAN-06-4149

35. Budanov AV, Karin M (2008) p53 target genes sestrin1 and sestrin2 connect genotoxic stress and mTOR signaling. Cell 134:451-460. https://doi.org/10.1016/j.cell.2008.06.028

36. Vyas S, Zaganjor E, Haigis MC (2016) Mitochondria and cancer. Cell 166:555-566. https://doi.org/10.1016/j.cell.2016.07.002

37. Eiyama A, Okamoto K (2015) PINK1/Parkin-mediated mitophagy in mammalian cells. Curr Opin Cell Biol 33:95-101. https://doi.org/10.1016/j.ceb.2015.01.002

38. Ashrafi G, Schwarz TL (2013) The pathways of mitophagy for quality control and clearance of mitochondria. Cell Death Differ 20:31-42. https://doi.org/10.1038/cdd.2012.81

39. Kanki T, Wang K, Baba M, Bartholomew CR, Lynch-Day MA, Du Z, Geng J, Mao K, Yang Z, Yen W-L, Klionsky DJ (2009) A genomic screen for yeast mutants defective in selective mitochondria autophagy. Mol Biol Cell 20:4730-4738. https://doi. org/10.1091/mbc.E09-03-0225

40. Redmann M, Dodson M, Boyer-Guittaut M, Darley-Usmar V, Zhang J (2014) Mitophagy mechanisms and role in human diseases. Int J Biochem Cell Biol 53:127-133. https://doi. org/10.1016/j.biocel.2014.05.010

41. Chourasia AH, Tracy K, Frankenberger C, Boland ML, Sharifi MN, Drake LE, Sachleben JR, Asara JM, Locasale JW, Karczmar GS, Macleod KF (2015) Mitophagy defects arising from BNip3 loss promote mammary tumor progression to metastasis. EMBO Rep 16:1145-1163. https://doi.org/10.15252/embr.201540759

42. Yan C, Luo L, Guo CY, Goto S, Urata Y, Shao JH, Li TS (2017) Doxorubicin-induced mitophagy contributes to drug resistance in cancer stem cells from HCT8 human colorectal cancer cells. Cancer Lett 388:34-42. https://doi.org/10.1016/j.canle t.2016.11.018

43. Shintani T, Klionsky DJ (2004) Autophagy in health and disease: A double-edged sword. Science (80-.) 306:990-995. https://doi. org/10.1126/science.1099993

44. Dodson M, Darley-Usmar V, Zhang J (2013) Cellular metabolic and autophagic pathways: traffic control by redox signaling. Free Radic Biol Med 63:207-221. https://doi.org/10.1016/j.freeradbio med.2013.05.014

45. Deberardinis RJ, Thompson CB (2012) Cellular metabolism and disease: what do metabolic outliers teach us? Cell 148:11321144. https://doi.org/10.1016/j.cell.2012.02.032
46. Kondo Y, Kanzawa T, Sawaya R, Kondo S (2005) The role of autophagy in cancer development and response to therapy. Nat Rev Cancer 5:726-734. https://doi.org/10.1038/nrc1692

47. Singh SS, Vats S, Chia AY-Q, Tan TZ, Deng S, Ong MS, Arfuso F, Yap CT, Goh BC, Sethi G, Huang RY-J, Shen HM, Manjithaya R, Kumar AP (2018) Dual role of autophagy in hallmarks of cancer. Oncogene 37:1142-1158. https://doi.org/10.1038/s4138 8-017-0046-6

48. Fiorini C, Menegazzi M, Padroni C, Dando I, Dalla Pozza E, Gregorelli A, Costanzo C, Palmieri M, Donadelli M (2013) Autophagy induced by $\mathrm{p} 53$-reactivating molecules protects pancreatic cancer cells from apoptosis. Apoptosis 18:337-346. https ://doi.org/10.1007/s10495-012-0790-6

49. Bellot G, Garcia-Medina R, Gounon P, Chiche J, Roux D, Pouyssegur J, Mazure NM (2009) Hypoxia-induced autophagy is mediated through hypoxia-inducible factor induction of BNIP3 and BNIP3L via their BH3 domains. Mol Cell Biol 29:25702581. https://doi.org/10.1128/MCB.00166-09

50. Kimmelman AC (2011) The dynamic nature of autophagy in cancer. Genes Dev 25:1999-2010. https://doi.org/10.1101/ gad.17558811

51. Yang ZJ, Chee CE, Huang S, Sinicrope FA (2011) The role of autophagy in cancer: therapeutic implications. Mol Cancer Ther 10:1533-1541. https://doi.org/10.1158/1535-7163.MCT-11-0047

52. Kumari S, Badana AK, Murali MG, Shailender G, Malla R (2018) Reactive oxygen species: a key constituent in cancer survival, biomark. Insights 13:117727191875539. https://doi. org/10.1177/1177271918755391

53. Mathew R, Kongara S, Beaudoin B, Karp CM, Bray K, Degenhardt K, Chen G, Jin S, White E (2007) Chromosomal instability autophagy suppresses tumor progression by limiting chromosomal instability. Genes Dev. https://doi.org/10.1101/gad.15451 07

54. White E (2012) Deconvoluting the context-dependent role for autophagy in cancer. Nat Rev Cancer 12:401-410. https://doi. org/10.1038/nrc3262

55. Shen Y, Li DD, Wang LL, Deng R, Zhu XF (2008) Decreased expression of autophagy-related proteins in malignant epithelial ovarian cancer. Autophagy 4:1067-1068. https://doi.org/10.4161/ auto. 6827

56. Moscat J, Diaz-Meco MT (2009) p62 at the crossroads of autophagy, apoptosis, and cancer. Cell 137:1001-1004. https:// doi.org/10.1016/j.cell.2009.05.023

57. Liu J, Xia H, Kim M, Xu L, Li Y, Zhang L, Cai Y, Norberg HV, Zhang T, Furuya T, Jin M, Zhu Z, Wang H, Yu J, Li Y, Hao Y, Choi A, Ke H, Ma D, Yuan J (2011) Beclin1 controls the levels of $\mathrm{p} 53$ by regulating the deubiquitination activity of USP10 and USP13. Cell 147:223-234. https://doi.org/10.1016/j. cell.2011.08.037

58. Agarwal S, Bell CM, Taylor SM, Moran RG (2016) p53 deletion or hotspot mutations enhance mTORC1 activity by altering lysosomal dynamics of TSC2 and Rheb. Mol Cancer Res 14:66-77. https://doi.org/10.1158/1541-7786.MCR-15-0159

59. Tan BS, Tiong KH, Choo HL, Fei-Lei Chung F, Hii LW, Tan SH, Yap IKS, Pani S, Khor NTW, Wong SF, Rosli R, Cheong SK, Leong CO (2015) Mutant p53-R273H mediates cancer cell survival and anoikis resistance through AKT-dependent suppression of BCL2-modifying factor (BMF). Cell Death Dis. https:// doi.org/10.1038/cddis.2015.191

60. Cordani M, Oppici E, Dando I, Butturini E, Dalla Pozza E, Nadal-Serrano M, Oliver J, Roca P, Mariotto S, Cellini B, Blandino G, Palmieri M, Di Agostino S, Donadelli M (2016) Mutant p53 proteins counteract autophagic mechanism sensitizing cancer cells to mTOR inhibition. Mol Oncol 10:1008-1029. https://doi. org/10.1016/j.molonc.2016.04.001 
61. Zhou G, Wang J, Zhao M, Xie TX, Tanaka N, Sano D, Patel AA, Ward AM, Sandulache VC, Jasser SA, Skinner HD, Fitzgerald AL, Osman AA, Wei Y, Xia X, Songyang Z, Mills GB, Hung MC, Caulin C, Liang J, Myers JN (2014) Gain-of-function mutant p53 promotes cell growth and cancer cell metabolism via inhibition of AMPK activation. Mol Cell 54:960-974. https ://doi.org/10.1016/j.molcel.2014.04.024

62. Cordani M, Butera G, Pacchiana R, Donadelli M (1867) Molecular interplay between mutant $\mathrm{p} 53$ proteins and autophagy in cancer cells. Biochim Biophys Acta Rev Cancer 2017:19-28. https ://doi.org/10.1016/j.bbcan.2016.11.003

63. Popovic D, Vucic D, Dikic I (2014) Ubiquitination in disease pathogenesis and treatment. Nat Med 20:1242-1253. https://doi. org/10.1038/nm.3739

64. Martinez-Vicente M, Cuervo AM (2007) Autophagy and neurodegeneration: when the cleaning crew goes on strike. Lancet Neurol 6:352-361. https://doi.org/10.1016/S1474-4422(07)70076-5

65. Sandri M (2011) New findings of lysosomal proteolysis in skeletal muscle. Curr Opin Clin Nutr Metab Care 14:223-229. https ://doi.org/10.1097/MCO.0b013e3283457a75

66. Nishino I, Fu J, Tanji K, Yamada T, Shimojo S, Koori T, Mora M, Riggs JE, Oh SJ, Koga Y, Sue CM, Yamamoto A, Murakami N, Shanske S, Byrne E, Bonilla E, Honaka I, DiMauro S, Hirano M (2000) Primary LAMP-2 deficiency causes X-linked vacoular cardiomyopathy and myopathy (Danon disease). Nature 406:906-910. https://doi.org/10.1038/35022604

67. Fukuda T, Ahearn M, Roberts A, Mattaliano RJ, Zaal K, Ralston E, Plotz PH, Raben N (2006) Autophagy and mistargeting of therapeutic enzyme in skeletal muscle in Pompe disease. Mol Ther 14:831-839. https://doi.org/10.1016/j.ymthe.2006.08.009

68. Sandri M, Coletto L, Grumati P, Bonaldo P (2013) Misregulation of autophagy and protein degradation systems in myopathies and muscular dystrophies. J Cell Sci 126:5325-5333. https://doi. org/10.1242/jcs. 114041

69. Hu Y-L, DeLay M, Jahangiri A, Molinaro AM, Rose SD, Carbonell WS, Aghi MK (2012) Hypoxia-induced autophagy promotes tumor cell survival and adaptation to antiangiogenic treatment in glioblastoma. Cancer Res 72:1773-1783. https:// doi.org/10.1158/0008-5472.CAN-11-3831

70. Kenific CM, Thorburn A, Debnath J (2010) Autophagy and metastasis: another double-edged sword. Curr Opin Cell Biol 22:241-245. https://doi.org/10.1016/j.ceb.2009.10.008

71. Duffy A, Le J, Sausville E, Emadi A (2015) Autophagy modulation: a target for cancer treatment development. Cancer Chemother Pharmacol 75:439-447. https://doi.org/10.1007/s0028 $0-014-2637-z$

72. Cook KL, Shajahan AN, Clarke R (2011) Autophagy and endocrine resistance in breast cancer. Expert Rev Anticancer Ther 11:1283-1294. https://doi.org/10.1586/era.11.111

73. Jain K, Paranandi KS, Sridharan S, Basu A (2013) Autophagy in breast cancer and its implications for therapy. Am J Cancer Res 3:251-265. https://doi.org/10.1016/j.tcb.2014.09.001

74. Jin S, White E (2007) Role of autophagy in cancer: management of metabolic stress. Autophagy 3:28-31

75. Sui X, Chen R, Wang Z, Huang Z, Kong N, Zhang M, Han W, Lou F, Yang J, Zhang Q, Wang X, He C, Pan H (2013) Autophagy and chemotherapy resistance: a promising therapeutic target for cancer treatment. Cell Death Dis 4:e838. https://doi. org/10.1038/cddis.2013.350

76. Ronan B, Flamand O, Vescovi L, Dureuil C, Durand L, Fassy F, Bachelot MF, Lamberton A, Mathieu M, Bertrand T, Marquette JP, El-Ahmad Y, Filoche-Romme B, Schio L, Garcia-Echeverria C, Goulaouic H, Pasquier B, Thoreen CC, Kang SA, Chang JW, Liu Q, Zhang J, Gao Y, Reichling LJ, Sim T, Sabatini DM, Gray NS, Taniguchi M, Kitatani K, Kondo T, Hashimoto-Nishimura M, Asano S, Hayashi A, Mitsutake S, Igarashi Y, Umehara H,
Takeya H, Kigawa J, Okazaki T, Ponpuak M, Mandell MA, Kimura T, Chauhan S, Cleyrat C, Deretic V, Cell IF, Glucose W, Kumar A, Lawrence JC, Jung DY, Ko HJ, Keller SR, Kim JK, Magnuson MA, Harris TE, Torres-quiroz F, Filteau M, Landry CR, Dowdle WE, Nyfeler B, Nagel J, Elling RA, Liu S, Triantafellow E, Menon S, Wang Z, Honda A, Pardee G, Cantwell J, Luu C, Cornella-Taracido I, Harrington E, Fekkes P, Lei H, Fang Q, Digan ME, Burdick D, Powers AF, Helliwell SB, Daquin S, Bastien J, Wang H, Wiederschain D, Kuerth J, Bergman P, Schwalb D, Thomas J, Ugwonali S, Harbinski F, Tallarico J, Wilson CJ, Myer VE, Porter JA, Bussiere DE, Finan PM, Labow MA, Mao X, Hamann LG, Manning BD, Valdez RA, Nicholson T, Schirle M, Knapp MS, Keaney EP, Murphy LO, Soliman GA, Acosta-Jaquez HA, Fingar DC, Sarkar S, Mizushima N, Yoshimorim T, Levine B, Wu YT, Tan HL, Shui G, Bauvy C, Huang Q, Wenk MR, Ong CN, Codogno P, Shen HM, Yang YP, Hu LF, Zheng HF, Mao CJ, Hu WD, Xiong KP, Wang F, Liu CF, Committee E, Grijalva A, Xu X, Ferrante AW, Ugland H, Naderi S, Brech A, Collas P, Blomhoff HK, Chen Y, Klionsky DJ, Dupont N, Jiang S, Pilli M, Ornatowski W, Bhattacharya D, Deretic V, Alers S, Löffler AS, Paasch F, Dieterle AM, Keppeler H, Lauber K, Campbell DG, Fehrenbacher B, Schaller M, Wesselborg S, Stork B, Popelka H, Klionsky DJ, Sun K, Kusminski CCM, Scherer PEP, Humphrey SJ, Yang G, Yang P, Fazakerley DJ, Stöckli J, Yang JY, James DE, Heckmann BL, Yang X, Zhang X, Liu J, Goold R, McKinnon C, Rabbanian S, Collinge J, Schiavo G, Tabrizi SJ, Manjithaya R, Subramani S (2011) Application and interpretation of current autophagy inhibitors and activators. Autophagy 7:163-171. https://doi.org/10.1038/emboj.2011.398

77. Goldberg SB, Supko JG, Neal JW, Muzikansky A, Digumarthy S, Fidias P, Temel JS, Heist RS, Shaw AT, McCarthy PO, Lynch TJ, Sharma S, Settleman JE, Sequist LV (2012) A phase I study of erlotinib and hydroxychloroquine in advanced nonsmall-cell lung cancer. J Thorac Oncol 7:1602-1608. https://doi. org/10.1097/JTO.0b013e318262de4a

78. Lee HO, Mustafa A, Hudes GR, Kruger WD (2015) Hydroxychloroquine destabilizes phospho-S6 in human renal carcinoma cells. PLoS One. https://doi.org/10.1371/journal.pone.0131464

79. Cook KL, Wärri A, Soto-Pantoja DR, Clarke PAG, Cruz MI, Zwart A, Clarke R (2014) Hydroxychloroquine inhibits autophagy to potentiate antiestrogen responsiveness in ER+ breast cancer. Clin Cancer Res 20:3222-3232. https://doi. org/10.1158/1078-0432.CCR-13-3227

80. Milano V, Piao Y, LaFortune T, de Groot J (2009) Dasatinibinduced autophagy is enhanced in combination with temozolomide in glioma. Mol Cancer Ther 8:394-406. https://doi. org/10.1158/1535-7163.MCT-08-0669

81. Liu YL, Yang PM, Shun CT, Wu MS, Weng JR, Chen CC (2010) Autophagy potentiates the anti-cancer effects of the histone deacetylase inhibitors in hepatocellular carcinoma. Autophagy 6:1057-1065. https://doi.org/10.4161/auto.6.8.13365

82. Zhu K, Dunner K, McConkey DJ (2010) Proteasome inhibitors activate autophagy as a cytoprotective response in human prostate cancer cells. Oncogene 29:451-462. https://doi.org/10.1038/ onc. 2009.343

83. Yazbeck VY, Buglio D, Georgakis GV, Li Y, Iwado E, Romaguera JE, Kondo S, Younes A (2008) Temsirolimus downregulates p21 without altering cyclin D1 expression and induces autophagy and synergizes with vorinostat in mantle cell lymphoma. Exp Hematol 36:443-450. https://doi.org/10.1016/j. exphem.2007.12.008

84. Crazzolara R, Cisterne A, Thien M, Hewson J, Baraz R, Bradstock KF, Bendall LJ (2009) Potentiating effects of RAD001 (Everolimus) on vincristine therapy in childhood acute lymphoblastic leukemia. Blood 113:3297-3306. https://doi.org/10.1182/ blood-2008-02-137752 
85. Guba M, Von Breitenbuch P, Steinbauer M, Koehl G, Flegel S, Hornung M, Bruns CJ, Zuelke C, Farkas S, Anthuber M, Jauch KW, Geissler EK (2002) Rapamycin inhibits primary and metastatic tumor growth by antiangiogenesis: involvement of vascular endothelial growth factor. Nat Med 8:128-135. https://doi. org/10.1038/nm0202-128

86. Motzer RJ, Escudier B, Oudard S, Hutson TE, Porta C, Bracarda S, Grünwald V, Thompson JA, Figlin RA, Hollaender N, Urbanowitz G, Berg WJ, Kay A, Lebwohl D, Ravaud A (2008) Efficacy of everolimus in advanced renal cell carcinoma: a double-blind, randomised, placebo-controlled phase III trial. Lancet 372:449-456. https://doi.org/10.1016/S0140-6736(08)61039-9

87. Xie X, White EP, Mehnert JM (2013) Coordinate autophagy and mTOR pathway inhibition enhances cell death in melanoma. PLoS One. https://doi.org/10.1371/journal.pone.0055096

88. Rosich L, Xargay-Torrent S, López-Guerra M, Campo E, Colomer D, Roué G (2012) Counteracting autophagy overcomes resistance to everolimus in mantle cell lymphoma. Clin Cancer Res 18:5278-5289. https://doi.org/10.1158/1078-0432. CCR-12-0351

89. Conde J, Doria G, Baptista P (2012) Noble metal nanoparticles applications in cancer. J Drug Deliv 2012:1-12. https://doi. org/10.1155/2012/751075

90. Sun T, Zhang YS, Pang B, Hyun DC, Yang M, Xia Y (2014) Engineered nanoparticles for drug delivery in cancer therapy. Angew Chem Int Ed 53:12320-12364. https://doi.org/10.1002/ anie. 201403036

91. Hong H, Shi J, Yang Y, Zhang Y, Engle JW, Nickles RJ, Wang X, Cai W (2011) Cancer-targeted optical imaging with fluorescent zinc oxide nanowires. Nano Lett 11:3744-3750. https://doi. org/10.1021/nl201782m

92. Pagliari F, Mandoli C, Forte G, Magnani E, Pagliari S, Nardone G, Licoccia S, Minieri M, Di Nardo P, Traversa E (2012) Cerium oxide nanoparticles protect cardiac progenitor cells from oxidative stress. ACS Nano 6:3767-3775. https://doi.org/10.1021/ nn2048069

93. Partha R, Mitchell LR, Lyon JL, Joshi PP, Conyers JL (2008) Buckysomes: fullerene-based nanocarriers for hydrophobic molecule delivery. ACS Nano 2:1950-1958. https://doi.org/10.1021/ nn800422k

94. Yang W, Thordarson P, Gooding JJ, Ringer SP, Braet F (2001) Carbon nanotubes for biological and biomedical applications 41:2007. https://doi.org/10.1088/0957-4484/18/41/412001

95. Williams KA, Veenhuizen PTM, De la Torre BG, Eritja R, Dekker C (2002) Nanotechnology: carbon nanotubes with DNA recognition. Nature 420:761. https://doi.org/10.1038/420761a

96. Matsumura Y, Kataoka K (2009) Preclinical and clinical studies of anticancer agent-incorporating polymer micelles. Cancer Sci 100:572-579. https://doi.org/10.1111/j.1349-7006.2009.01103.x

97. Dreaden EC, Alkilany AM, Huang X, Murphy CJ, El-Sayed MA (2012) The golden age: gold nanoparticles for biomedicine. Chem Soc Rev 41:2740-2779. https://doi.org/10.1039/C1CS1 $5237 \mathrm{H}$

98. Bhattacharya R, Mukherjee P (2008) Biological properties of "naked" metal nanoparticles. Adv Drug Deliv Rev 60:12891306. https://doi.org/10.1016/j.addr.2008.03.013

99. Jain S, Hirst DG, O'Sullivan JM (2012) Gold nanoparticles as novel agents for cancer therapy. Br J Radiol 85:101-113. https:// doi.org/10.1259/bjr/59448833

100. Albanese A, Tang PS, Chan WCW (2012) The effect of nanoparticle size, shape, and surface chemistry on biological systems. Annu Rev Biomed Eng 14:1-16. https://doi.org/10.1146/annur ev-bioeng-071811-150124

101. Liu Y, Solomon M, Achilefu S (2013) Perspectives and potential applications of nanomedicine in breast and prostate cancer. Med Res Rev 33:3-32. https://doi.org/10.1002/med
102. Cho K, Wang X, Nie S, Chen ZG, Shin DM (2008) Therapeutic nanoparticles for drug delivery in cancer. Clin Cancer Res 14:1310-1316. https://doi.org/10.1158/1078-0432.CCR-07-1441

103. Bañobre-López M, Teijeiro A, Rivas J (2013) Magnetic nanoparticle-based hyperthermia for cancer treatment. Rep Pract Oncol Radiother 18:397-400. https://doi.org/10.1016/j. rpor.2013.09.011

104. Andrä W, Nowak H (2006) Magnetism in Medicine: a Handbook, 2nd edn. WILEY-VCH Verlag GmbH \& Co. KGaA, Weinheim. https://doi.org/10.1002/9783527610174

105. Giustini AJ, Petryk AA, Cassim SM, Tate JA, Baker I, Hoopes PJ (2010) Magnetic nanoparticle hyperthermia in cancer treatment. Nano Life 01:17-32. https://doi.org/10.1142/S1793 984410000067

106. Huang X, Jain PK, El-Sayed IH, El-Sayed MA (2008) Plasmonic photothermal therapy (PPTT) using gold nanoparticles. Lasers Med Sci 23:217-228. https://doi.org/10.1007/s1010 3-007-0470-x

107. Chu M, Shao Y, Peng J, Dai X, Li H, Wu Q, Shi D (2013) Nearinfrared laser light mediated cancer therapy by photothermal effect of $\mathrm{Fe}_{3} \mathrm{O}_{4}$ magnetic nanoparticles. Biomaterials 34:40784088. https://doi.org/10.1016/j.biomaterials.2013.01.086

108. Bernardi RJ, Lowery AR, Thompson PA, Blaney SM, West JL (2008) Immunonanoshells for targeted photothermal ablation in medulloblastoma and glioma: an in vitro evaluation using human cell lines. J Neurooncol 86:165-172. https://doi. org/10.1007/s11060-007-9467-3

109. Cheng FY, Chen CT, Yeh CS (2009) Comparative efficiencies of photothermal destruction of malignant cells using antibodycoated silica@Au nanoshells, hollow Au/Ag nanospheres and Au nanorods. Nanotechnology. https://doi.org/10.1088/09574484/20/42/425104

110. Dickerson EB, Dreaden EC, Huang X, El-Sayed IH, Chu H, Pushpanketh S, McDonald JF, El-Sayed MA (2008) Gold nanorod assisted near-infrared plasmonic photothermal therapy (PPTT) of squamous cell carcinoma in mice. Cancer Lett 269:57-66. https://doi.org/10.1016/j.canlet.2008.04.026

111. Diagaradjane P, Shetty A, Wang JC, Elliott AM, Schwartz J, Shentu S, Park HC, Deorukhkar A, Stafford RJ, Cho SH, Tunnell JW, Hazle JD, Krishnan S (2008) Modulation of in vivo tumor radiation response via gold nanoshell-mediated vascular-focused hyperthermia: characterizing an integrated antihypoxic and localized vascular disrupting targeting strategy. Nano Lett 8:1492-1500. https://doi.org/10.1021/nl080496z

112. Buttacavoli M, Albanese NN, Di Cara G, Alduina R, Faleri C, Gallo M, Pizzolanti G, Gallo G, Feo S, Baldi F, Cancemi P (2018) Anticancer activity of biogenerated silver nanoparticles: an integrated proteomic investigation. Oncotarget. 9:9685-9705. https://doi.org/10.18632/oncotarget.23859

113. Zielinska E, Zauszkiewicz-pawlak A, Wojcik M (2017) Silver nanoparticles of different sizes induce a mixed type of programmed cell death in human pancreatic ductal adenocarcinoma. Oncotarget. https://doi.org/10.18632/oncotarget.22563 (epub ahed of print)

114. Yuan YG, Gurunathan S (2017) Combination of graphene oxide-silver nanoparticle nanocomposites and cisplatin enhances apoptosis and autophagy in human cervical cancer cells. Int J Nanomed 12:6537-6558. https://doi.org/10.2147/ IJN.S 125281

115. Zhang X-F, Gurunathan S (2016) Combination of salinomycin and silver nanoparticles enhances apoptosis and autophagy in human ovarian cancer cells: an effective anticancer therapy. Int J Nanomed 11:3655-3675. https://doi.org/10.2147/IJN.S111279

116. Liu P, Jin H, Guo Z, Ma J, Zhao J, Li D, Wu H, Gu N (2016) Silver nanoparticles outperform gold nanoparticles in radiosensitizing U251 cells in vitro and in an intracranial mouse model of 
glioma. Int J Nanomed 11:5003-5014. https://doi.org/10.2147/ IJN.S115473

117. Zhu L, Guo D, Sun L, Huang Z, Zhang X, Ma W, Wu J, Xiao L, Zhao Y, Gu N (2017) Activation of autophagy by elevated reactive oxygen species rather than released silver ions promotes cytotoxicity of polyvinylpyrrolidone-coated silver nanoparticles in hematopoietic cells. Nanoscale 9:5489-5498. https://doi. org/10.1039/c6nr08188f

118. Mishra AR, Zheng J, Tang X, Goering PL (2016) Silver nanoparticle-induced autophagic-Lysosomal disruption and NLRP3inflammasome activation in HepG2 cells is size-dependent. Toxicol Sci 150:473-487. https://doi.org/10.1093/toxsci/kfw011

119. Jeong JK, Gurunathan S, Kang MH, Han JW, Das J, Choi YJ, Kwon DN, Cho SG, Park C, Seo HG, Song H, Kim JH (2016) Hypoxia-mediated autophagic flux inhibits silver nanoparticletriggered apoptosis in human lung cancer cells. Sci Rep. https:// doi.org/10.1038/srep21688

120. Fageria L, Pareek V, Dilip RV, Bhargava A, Pasha SS, Laskar IR, Saini H, Dash S, Chowdhury R, Panwar J (2017) Biosynthesized protein-capped silver nanoparticles induce ROS-dependent proapoptotic signals and prosurvival autophagy in cancer cells. ACS Omega 2:1489-1504. https://doi.org/10.1021/acsomega.7b000 45

121. Settembre C, Di Malta C, Polito VA, Arencibia MG, Vetrini F, Erdin S, Erdin SU, Huynh T, Medina D, Colella P, Sardiello M, Rubinsztein DC, Ballabio A (2011) TFEB links autophagy to lysosomal biogenesis. Science (80-.) 332:1429-1433. https://doi. org/10.1126/science. 1204592

122. Settembre C, Ballabio A (2011) TFEB regulates autophagy: an integrated coordination of cellular degradation and recycling processes. Autophagy 7:1379-1381. https://doi.org/10.4161/ auto.7.11.17166

123. Miyayama T, Fujiki K, Matsuoka M (2018) Silver nanoparticles induce lysosomal-autophagic defects and decreased expression of transcription factor EB in A549 human lung adenocarcinoma cells. Toxicol Vitro 46:148-154. https://doi.org/10.1016/j. tiv.2017.10.009

124. Eck W, Craig G, Sigdel A, Ritter G, Old LJ, Tang L, Brennan MF, Allen PJ, Mason MD (2008) PEGylated gold nanoparticles conjugated to monoclonal F19 antibodies as targeted labeling agents for human pancreatic carcinoma tissue. ACS Nano 2:2263-2272. https://doi.org/10.1021/nn800429d

125. Connor EE, Mwamuka J, Gole A, Murphy CJ, Wyatt MD (2005) Gold nanoparticles are taken up by human cells but do not cause acute cytotoxicity. Small 1:325-327. https://doi.org/10.1002/ smll.200400093

126. Klassen NV, Kedrov VV, Ossipyan YA, Shmurak SZ, Shmytńko IM, Krivko OA, Kudrenko EA, Kurlov VN, Kobelev NP, Kiselev AP, Bozhko SI (2009) Nanoscintillators for microscopic diagnostics of biological and medical objects and medical therapy. IEEE Trans Nanobiosci 8:20-32. https://doi.org/10.1109/ TNB.2009.2016551

127. Lin YX, Gao YJ, Wang Y, Qiao ZY, Fan G, Qiao SL, Zhang RX, Wang L, Wang H (2015) pH-sensitive polymeric nanoparticles with gold(I) compound payloads synergistically induce cancer cell death through modulation of autophagy. Mol Pharm 12:2869-2878. https://doi.org/10.1021/acs.molpharmac eut.5b00060

128. Koken MHM, Smit EME, Jaspers-Dekker I, Oostra BA, Hagemeuer A, Bootsma D, Hoeumakers JHJ (1992) Localization of two human homologs, HHR6A and HHR6B, of the yeast DNA repair gene RAD6 to chromosomes Xq24-q25 and 5q23q31. Genomics 12:447-453. https://doi.org/10.1016/08887543(92)90433-S

129. Koken MH, Reynolds P, Jaspers-Dekker I, Prakash L, Prakash S, Bootsma D, Hoeijmakers JH (1991) Structural and functional conservation of two human homologs of the yeast DNA repair gene RAD6. Proc Natl Acad Sci USA 88:8865-8869. https://doi. org/10.1073/pnas.88.20.8865

130. Haynes B, Zhang Y, Liu F, Li J, Petit S, Bao X, Westwell AD, Mao G, Building R (2016) Gold nanoparticle conjugated Rad6 inhibitor induces cell death in triple negative breast cancer cells by inducing mitochondrial dysfunction and PARP-1 hyperactivation: synthesis and characterization. Nanomedicine 12:745-757. https://doi.org/10.1016/j.nano.2015.10.010.Gold

131. Bhowmik T, Gomes A (2016) NKCT1 (purified Naja kaouthia protein toxin) conjugated gold nanoparticles induced Akt/ mTOR inactivation mediated autophagic and caspase 3 activated apoptotic cell death in leukemic cell. Toxicon 121:86-97. https://doi.org/10.1016/j.toxicon.2016.08.004

132. Ke S, Zhou T, Yang P, Wang Y, Zhang P, Chen K, Ren L, Ye S (2017) Gold nanoparticles enhance TRAIL sensitivity through Drp1-mediated apoptotic and autophagic mitochondrial fission in NSCLC cells. Int J Nanomed 12:2531-2551. https://doi. org/10.2147/IJN.S129274

133. Crown J, O’Shaughnessy J, Gullo G (2012) Emerging targeted therapies in triple-negative breast cancer. Ann Oncol. https:// doi.org/10.1093/annonc/mds196

134. Zhang M, Kim HS, Jin T, Moon WK (2017) Near-infrared photothermal therapy using EGFR-targeted gold nanoparticles increases autophagic cell death in breast cancer. J Photochem Photobiol B Biol 170:58-64. https://doi.org/10.1016/j.jphot obiol.2017.03.025

135. Slamon DJ, Leyland-Jones B, Shak S, Fuchs H, Paton V, Bajamonde A, Fleming T, Eiermann W, Wolter J, Pegram M, Baselga J, Norton L (2001) Use of chemotherapy plus a monoclonal antibody against HER 2 for metastatic breast cancer that overexpresses HER2. N Engl J Med 344:783-792. https://doi. org/10.1056/NEJM200103153441101

136. Kubota T, Kuroda S, Kanaya N, Morihiro T, Aoyama K, Yoshihiko K, Kikuchi S, Nishizaki M, Kagawa S, Tazawa H, Fujiwara T (2018) HER2-targeted gold nanoparticles potentially overcome resistance to trastuzumab in gastric cancer. Nanomed Nanotechnol Biol Med. https://doi.org/10.1016/j. nano.2018.05.019 (\#pagerange\#)

137. Formica JV, Regelson W (1995) Review of the biology of quercetin and related bioflavonoids. Food Chem Toxicol 33:1061-1080. https://doi.org/10.1016/0278-6915(95)00077-1

138. Rauf A, Imran M, Khan IA, ur-Rehman M, Gilani SA, Mehmood Z, Mubarak MS (2018) Anticancer potential of quercetin: a comprehensive review. Phyther Res. https://doi. org/10.1002/ptr.6155

139. Ren K-W, Li Y-H, Wu G, Ren J-Z, Lu H-B, Li Z-M, Han X-W (2017) Quercetin nanoparticles display antitumor activity via proliferation inhibition and apoptosis induction in liver cancer cells. Int J Oncol 50:1299-1311. https://doi.org/10.3892/ ijo.2017.3886

140. Lou M, Na Zhang L, Gang Ji P, Qiang Feng F, Hui Liu J, Yang C, Fu Li B, Wang L (2016) Quercetin nanoparticles induced autophagy and apoptosis through AKT/ERK/caspase-3 signaling pathway in human neuroglioma cells: in vitro and in vivo. Biomed Pharmacother 84:1-9. https://doi.org/10.1016/j.bioph a.2016.08.055

141. Lin Luo C, Qiong Liu Y, Wang P, Hua Song C, Juan Wang K, Ping Dai L, Ying Zhang J, Ye H (2016) The effect of quercetin nanoparticle on cervical cancer progression by inducing apoptosis, autophagy and anti-proliferation via JAK2 suppression. Biomed Pharmacother 82:595-605. https://doi.org/10.1016/j. biopha.2016.05.029

142. Yuan L, Zhang F, Qi X, Yang Y, Yan C, Jiang J, Deng J (2018) Chiral polymer modified nanoparticles selectively induce 
autophagy of cancer cells for tumor ablation. J Nanobiotechnol. https://doi.org/10.1186/s12951-018-0383-9

143. Carpenter EE, Sangregorio C, Connor CJ (1999) Effects of shell thickness on blocking temperature of nanocomposites of metal particles with gold shells. IEEE Trans Magn 35:3496-3498. https ://doi.org/10.1109/20.800568

144. Wu YN, Yang LX, Shi XY, Li IC, Biazik JM, Ratinac KR, Chen DH, Thordarson P, Bin Shieh D, Braet F (2011) The selective growth inhibition of oral cancer by iron core-gold shell nanoparticles through mitochondria-mediated autophagy. Biomaterials 32:4565-4573. https://doi.org/10.1016/j.biomateria 1s.2011.03.006

145. Wu Y-N, Wu P-C, Yang L-X, Ratinac KR, Thordarson P, Jahn KA, Chen D-H, Shieh D-B, Braet F (2013) The anticancer properties of iron core-gold shell nanoparticles in colorectal cancer cells. Int J Nanomed 8:3321-3331. https://doi.org/10.2147/IJN. S47742

146. Rasmussen JW, Martinez E, Louka P, Wingett DG (2010) Zinc oxide nanoparticles for selective destruction of tumor cells and potential for drug delivery applications. Expert Opin Drug Deliv 7:1063-1077. https://doi.org/10.1517/17425247.2010.502560

147. Bai D-P, Zhang X-F, Zhang G-L, Huang Y-F, Gurunathan S (2017) Zinc oxide nanoparticles induce apoptosis and autophagy in human ovarian cancer cells. Int J Nanomed 12:6521-6535. https://doi.org/10.2147/IJN.S140071

148. Wang J, Gao S, Wang S, Xu Z, Wei L (2018) Zinc oxide nanoparticles induce toxicity in CAL 27 oral cancer cell lines by activating PINK1/Parkin-mediated mitophagy. Int J Nanomed 13:3441-3450. https://doi.org/10.2147/IJN.S165699

149. Mozdoori N, Safarian S, Sheibani N (2017) Augmentation of the cytotoxic effects of zinc oxide nanoparticles by MTCP conjugation: non-canonical apoptosis and autophagy induction in human adenocarcinoma breast cancer cell lines. Mater Sci Eng C. https ://doi.org/10.1016/j.msec.2017.03.300

150. Yang C, He X, Song L, Zhan X, Zhang Y, Dou J, Gu N (2014) Gamma- $\mathrm{Fe}_{2} \mathrm{O}_{3}$ nanoparticles increase therapeutic efficacy of combination with paclitaxel and anti-ABCG2 monoclonal antibody on multiple myeloma cancer stem cells in mouse model. J Biomed Nanotechnol 10:336-344

151. Zhang X, Zhang H, Liang X, Zhang J, Tao W, Zhu X, Chang D, Zeng X, Liu G, Mei L (2016) Iron oxide nanoparticles induce autophagosome accumulation through multiple mechanisms: lysosome impairment, mitochondrial damage, and ER stress. Mol Pharm 13:2578-2587. https://doi.org/10.1021/acs.molph armaceut.6b00405

152. Kuroda S, Tam J, Roth JA, Sokolov K, Ramesh R (2014) EGFRtargeted plasmonic magnetic nanoparticles suppress lung tumor growth by abrogating G2/M cell-cycle arrest and inducing DNA damage. Int J Nanomed 9:3825-3839. https://doi.org/10.2147/ IJN.S65990

153. Li X, Feng J, Zhang R, Wang J, Su T, Tian Z, Han D, Zhao C, Fan M, Li C, Liu B, Feng X, Nie Y, Wu K, Chen Y, Deng H, Feng C (2016) Quaternized chitosan/alginate- $\mathrm{Fe}_{3} \mathrm{O}_{4}$ magnetic nanoparticles enhance the chemosensitization of multidrugresistant gastric carcinoma by regulating cell autophagy activity in mice. J Biomed Nanotechnol 12:948-961. https://doi. org/10.1166/jbn.2016.2232

154. Khan MI, Mohammad A, Patil G, Naqvi SAH, Chauhan LKS, Ahmad I (2012) Induction of ROS, mitochondrial damage and autophagy in lung epithelial cancer cells by iron oxide nanoparticles. Biomaterials 33:1477-1488. https://doi.org/10.1016/j. biomaterials.2011.10.080

155. Huang D, Zhou H, Gao J (2015) Nanoparticles modulate autophagic effect in a dispersity-dependent manner. Sci Rep 5:14361. https://doi.org/10.1038/srep14361
156. Feng Q, Liu Y, Huang J, Chen K, Huang J, Xiao K (2018) Uptake, distribution, clearance, and toxicity of iron oxide nanoparticles with different sizes and coatings. Sci Rep 8:1-13. https ://doi.org/10.1038/s41598-018-19628-Z

157. Ren X, Chen Y, Peng H, Fang X, Zhang X, Chen Q, Wang X, Yang W, Sha X (2018) Blocking autophagic flux enhances iron oxide nanoparticles photothermal therapeutic efficiency in cancer treatment. ACS Appl Mater Interfaces. https://doi.org/10.1021/ acsami.8b10167

158. Wang Y, Zi X-Y, Su J, Zhang H-X, Zhang X-R, Zhu H-Y, Li J-X, Yin M, Yang F, Hu Y-P (2012) Cuprous oxide nanoparticles selectively induce apoptosis of tumor cells. Int J Nanomed 7:2641-2652. https://doi.org/10.2147/IJN.S31133

159. Wang Y, Yang F, Zhang H-X, Zi X-Y, Pan X-H, Chen F, Luo W-D, Li J-X, Zhu H-Y, Hu Y-P (2013) Cuprous oxide nanoparticles inhibit the growth and metastasis of melanoma by targeting mitochondria. Cell Death Dis 4:e783. https://doi.org/10.1038/ cddis. 2013.314

160. Sun T, Yan Y, Zhao Y, Guo F, Jiang C (2012) Copper oxide nanoparticles induce autophagic cell death in a549 cells. PLoS One. https://doi.org/10.1371/journal.pone.0043442

161. Abudayyak M, Guzel EE, Özhan G (2016) Copper (II) oxide nanoparticles induced nephrotoxicity in vitro conditions. Appl Vitro Toxicol 2:157-164. https://doi.org/10.1089/aivt.2016.0008

162. Xia L, Wang Y, Chen Y, Yan J, Hao F, Su X, Zhang C, Xu M (2017) Cuprous oxide nanoparticles inhibit the growth of cervical carcinoma by inducing autophagy. Oncotarget 8:6108361092. https://doi.org/10.18632/oncotarget.17854

163. Laha D, Pramanik A, Maity J, Mukherjee A, Pramanik P, Laskar A, Karmakar P (2014) Interplay between autophagy and apoptosis mediated by copper oxide nanoparticles in human breast cancer cells MCF7. Biochim Biophys Acta 1840:1-9. https:// doi.org/10.1016/j.bbagen.2013.08.011

164. Roggers R, Kanvinde S, Boonsith S, Oupický D (2014) The practicality of mesoporous silica nanoparticles as drug delivery devices and progress toward this goal. AAPS PharmSciTech 15:1163-1171. https://doi.org/10.1208/s12249-014-0142-7

165. Napierska D, Thomassen LCJ, Rabolli V, Lison D, Gonzalez L, Kirsch-Volders M, Martens JA, Hoet PH (2009) Size-dependent cytotoxicity of monodisperse silica nanoparticles in human endothelial cells. Small 5:846-853. https://doi.org/10.1002/ smll.200800461

166. Thomassen LCJ, Aerts A, Rabolli V, Lison D, Gonzalez L, Kirsch-Volders M, Napierska D, Hoet PH, Kirschhock CEA, Martens JA (2010) Synthesis and characterization of stable monodisperse silica nanoparticle sols for in vitro cytotoxicity testing. Langmuir 26:328-335. https://doi.org/10.1021/la902 050k

167. Ha SW, Neale Weitzmann M, Beck GR (2014) Bioactive silica nanoparticles promote osteoblast differentiation through stimulation of autophagy and direct association with LC3 and p62. ACS Nano 8:5898-5910. https://doi.org/10.1021/nn5009879

168. Wang J, Li Y, Duan J, Yang M, Yu Y, Feng L, Yang X, Zhou X, Zhao Z, Sun Z (2018) Silica nanoparticles induce autophagosome accumulation via activation of the EIF2AK3 and ATF6 UPR pathways in hepatocytes. Autophagy. https://doi. org/10.1080/15548627.2018.1458174

169. Krętowski R, Kusaczuk M, Naumowicz M, Kotyńska J, Szynaka B, Cechowska-Pasko M (2017) The effects of silica nanoparticles on apoptosis and autophagy of glioblastoma cell lines. Nanomaterials (Basel, Switzerland). https://doi.org/10.3390/nano708023 0

170. Schütz I, Lopez-Hernandez T, Gao Q, Puchkov D, JaBerlinbs S, Nordmeyer D, Schmudde M, Rühl E, Graf CM, Haucke V (2016) Lysosomal dysfunction caused by cellular accumulation 
of silica nanoparticles. J Biol Chem 291:14170-14184. https:// doi.org/10.1074/jbc.M115.710947

171. Pool H, Campos-Vega R, Herrera-Hernández MG, García-Solis P, García-Gasca T, Sánchez IC, Luna-Bárcenas G, VergaraCastañeda H (2018) Development of genistein-PEGylated silica hybrid nanomaterials with enhanced antioxidant and antiproliferative properties on HT29 human colon cancer cells. Am J Transl Res 10:2306-2323

172. Wang J, Yu Y, Lu K, Yang M, Li Y, Zhou X, Sun Z (2017) Silica nanoparticles induce autophagy dysfunction via lysosomal impairment and inhibition of autophagosome degradation in hepatocytes. Int J Nanomed 12:809-825. https://doi.org/10.2147/ IJN.S123596

173. Yu Y, Duan J, Yu Y, Li Y, Liu X, Zhou X, Fai Ho K, Tian L, Sun Z (2014) Silica nanoparticles induce autophagy and autophagic cell death in HepG2 cells triggered by reactive oxygen species. J Hazard Mater 270:176-186. https://doi.org/10.1016/j.jhazm at.2014.01.028

174. Wei F, Wang Y, Luo Z, Li Y, Duan Y (2017) New findings of silica nanoparticles induced ER autophagy in human colon cancer cell. Sci Rep 7:1-11. https://doi.org/10.1038/srep42591

175. Lipatova Z, Segev N (2015) A role for macro-ER-phagy in ER quality control. PLoS Genet 11:1. https://doi.org/10.1371/journ al.pgen. 1005390

176. Lipatova Z, Shah AH, Kim JJ, Mulholland JW, Segev N (2013) Regulation of ER-phagy by a Ypt/Rab GTPase module. Mol Biol Cell 24:3133-3144. https://doi.org/10.1091/mbc.E13-05-0269

177. Schubert D, Dargusch R, Raitano J, Chan SW (2006) Cerium and yttrium oxide nanoparticles are neuroprotective. Biochem Biophys Res Commun 342:86-91. https://doi.org/10.1016/j. bbrc.2006.01.129

178. Das M, Patil S, Bhargava N, Kang JF, Riedel LM, Seal S, Hickman JJ (2007) Auto-catalytic ceria nanoparticles offer neuroprotection to adult rat spinal cord neurons. Biomaterials 28:19181925. https://doi.org/10.1016/j.biomaterials.2006.11.036

179. Song W, Soo Lee S, Savini M, Popp L, Colvin VL, Segatori L (2014) Ceria nanoparticles stabilized by organic surface coatings activate the lysosome-autophagy system and enhance autophagic clearance. ACS Nano 8:10328-10342. https://doi.org/10.1021/ nn505073u

180. Wei PF, Zhang L, Nethi SK, Barui AK, Lin J, Zhou W, Shen Y, Man N, Zhang YJ, Xu J, Patra CR, Wen LP (2014) Accelerating the clearance of mutant huntingtin protein aggregates through autophagy induction by europium hydroxide nanorods. Biomaterials 35:899-907. https://doi.org/10.1016/j.biomateria 1s.2013.10.024

181. Bibee KP, Cheng YJ, Ching JK, Marsh JN, Li AJ, Keeling RM, Connolly AM, Golumbek PT, Myerson JW, Hu G, Chen J, Shannon WD, Lanza GM, Weihl CC, Wickline SA (2014) Rapamycin nanoparticles target defective autophagy in muscular dystrophy to enhance both strength and cardiac function. FASEB J 28:2047-2061. https://doi.org/10.1096/fj.13-237388

182. Lin J, Huang Z, Wu H, Zhou W, Jin P, Wei P, Zhang Y, Zheng F, Zhang J, Xu J, Hu Y, Wang Y, Li Y, Gu N, Wen L (2014) Inhibition of autophagy enhances the anticancer activity of silver nanoparticles. Autophagy 10:2006-2020. https://doi.org/10.4161/ auto.36293

183. Wu Q, Jin R, Feng T, Liu L, Yang L, Tao Y, Anderson JM, Ai $\mathrm{H}, \mathrm{Li} \mathrm{H}$ (2017) Iron oxide nanoparticles and induced autophagy in human monocytes. Int J Nanomed 12:3993-4005. https://doi. org/10.2147/IJN.S135189

184. Blanco J, Tomás-Hernández S, García T, Mulero M, Gómez M, Domingo JL, Sánchez DJ (2018) Oral exposure to silver nanoparticles increases oxidative stress markers in the liver of male rats and deregulates the insulin signalling pathway and p53 and cleaved caspase 3 protein expression. Food Chem Toxicol 115:398-404. https://doi.org/10.1016/j.fct.2018.03.039

185. Wu H, Lin J, Liu P, Huang Z, Zhao P, Jin H, Ma J, Wen L, Gu $\mathrm{N}$ (2016) Reactive oxygen species acts as executor in radiation enhancement and autophagy inducing by AgNPs. Biomaterials 101:1-9. https://doi.org/10.1016/j.biomaterials.2016.05.031

186. Shi M, Cheng L, Zhang Z, Liu Z, Mao X (2015) Ferroferric oxide nanoparticles induce prosurvival autophagy in human blood cells by modulating the Beclin 1/Bcl-2/VPs34 complex. Int J Nanomed 10:207-216. https://doi.org/10.2147/IJN.S72598

187. Nowak JS, Mehn D, Nativo P, García CP, Gioria S, Ojea-Jiménez I, Gilliland D, Rossi F (2014) Silica nanoparticle uptake induces survival mechanism in A549 cells by the activation of autophagy but not apoptosis. Toxicol Lett 224:84-92. https://doi. org/10.1016/j.toxlet.2013.10.003

188. Voicu SNP, Dinu D, Sima C, Hermenean A, Ardelean A, Codrici E, Stan MS, Zărnescu O, Dinischiotu A (2015) Silica nanoparticles induce oxidative stress and autophagy but not apoptosis in the MRC-5 cell line. Int J Mol Sci 16:29398-29416. https://doi. org/10.3390/ijms 161226171

189. Shen TP, Zhu WC, Yang L, Liu L, Jin RR, Duan JM, Anderson JM, Ai H (2018) Lactosylated $N$-alkyl polyethylenimine coated iron oxide nanoparticles induced autophagy in mouse dendritic cells. Regen Biomater 5:141-149. https://doi.org/10.1093/rb/ rbx032

190. Liu Y, Yu H, Zhang X, Wang Y, Song Z, Zhao J, Shi H, Li R, Wang Y, Zhang LW (2018) The protective role of autophagy in nephrotoxicity induced by bismuth nanoparticles through AMPK/mTOR pathway. Nanotoxicology 12:586-601. https:// doi.org/10.1080/17435390.2018.1466932

191. Lin J, Liu Y, Wu H, Huang Z, Ma J, Guo C, Gao F, Jin P, Wei P, Zhang Y, Liu L, Zhang R, Qiu L, Gu N, Wen L (2018) Key role of TFEB nucleus translocation for silver nanoparticleinduced cytoprotective autophagy. Small 14:1-10. https://doi. org/10.1002/smll.201703711

192. Duan J, Yu Y, Yu Y, Li Y, Wang J, Geng W, Jiang L, Li Q, Zhou X, Sun Z (2014) Silica nanoparticles induce autophagy and endothelial dysfunction via the PI3K/Akt/mTOR signaling pathway. Int J Nanomed 9:5131-5141. https://doi.org/10.2147/ IJN.S71074

193. Guo C, Yang M, Jing L, Wang J, Yu Y, Li Y, Duan J, Zhou X, Li Y (2016) Amorphous silica nanoparticles trigger vascular endothelial cell injury through apoptosis and autophagy via reactive oxygen species-mediated MAPK/Bcl-2 and PI3K/Akt/ mTOR signaling. Int J Nanomed 11:5257-5276. https://doi. org/10.2147/IJN.S112030

194. Orlando A, Cazzaniga EM, Tringali M, Gullo F, Becchetti A, Minniti S, Taraballi F, Tasciotti E, Re F (2017) Mesoporous silica nanoparticles trigger mitophagy in endothelial cells and perturb neuronal network activity in a size- and time-dependent manner. Int J Nanomed 12:3547-3559. https://doi.org/10.2147/ IJN.S127663

195. Halamoda Kenzaoui B, Chapuis Bernasconi C, Guney-Ayra S, Juillerat-Jeanneret L (2012) Induction of oxidative stress, lysosome activation and autophagy by nanoparticles in human brainderived endothelial cells. Biochem J 441:813-821. https://doi. org/10.1042/bj20111252

196. Kim J-Y, Park J-H, Kim M, Jeong H, Hong J, Chuck RS, Park CY (2017) Safety of nonporous silica nanoparticles in human corneal endothelial cells. Sci Rep 7:14566. https://doi.org/10.1038/s4159 8-017-15247-2

197. Li Q, Hu H, Jiang L, Zou Y, Duan J, Sun Z (2016) Cytotoxicity and autophagy dysfunction induced by different sizes of silica particles in human bronchial epithelial BEAS-2B cells. Toxicol Res 5:1216-1228. https://doi.org/10.1039/C6TX00100A 
198. Xie H, Wu J (2016) Silica nanoparticles induce alpha-synuclein induction and aggregation in PC12-cells. Chem Biol Interact 258:197-204. https://doi.org/10.1016/j.cbi.2016.09.006

199. Zhang L, Wang XQ, Miao YM, Chen ZQ, Qiang PF, Cui LQ, Jing H, Guo YQ (2016) Magnetic ferroferric oxide nanoparticles induce vascular endothelial cell dysfunction and inflammation by disturbing autophagy. J Hazard Mater 304:186-195. https://doi. org/10.1016/j.jhazmat.2015.10.041

200. Song M, Zhang R, Dai Y, Gao F, Chi H, Lv G, Chen B, Wang X (2006) The in vitro inhibition of multidrug resistance by combined nanoparticulate titanium dioxide and UV irradition. Biomaterials 27:4230-4238. https://doi.org/10.1016/j.biomateria 1s.2006.03.021

201. Li Q, Wang X, Lu X, Tian H, Jiang H, Lv G, Guo D, Wu C, Chen B (2009) The incorporation of daunorubicin in cancer cells through the use of titanium dioxide whiskers. Biomaterials 30:4708-4715. https://doi.org/10.1016/j.biomateria 1s.2009.05.015

202. Chen Y, Wan Y, Wang Y, Zhang H, Jiao Z (2011) Anticancer efficacy enhancement and attenuation of side effects of doxorubicin with titanium dioxide nanoparticles. Int J Nanomed 6:2321-2326. https://doi.org/10.2147/IJN.S25460

203. Chihara Y, Fujimoto K, Kondo H, Moriwaka Y, Sasahira T, Hirao Y, Kuniyasu H (2007) Anti-tumor effects of liposome-encapsulated titanium dioxide in nude mice. Pathobiology 74:353-358. https://doi.org/10.1159/000110029

204. Lagopati N, Kitsiou PV, Kontos AI, Venieratos P, Kotsopoulou E, Kontos AG, Dionysiou DD, Pispas S, Tsilibary EC, Falaras P (2010) Photo-induced treatment of breast epithelial cancer cells using nanostructured titanium dioxide solution. J Photochem Photobiol A Chem 214:215-223. https://doi.org/10.1016/j.jphot ochem.2010.06.031

205. Lai TY, Lee WC (2009) Killing of cancer cell line by photoexcitation of folic acid-modified titanium dioxide nanoparticles. J Photochem Photobiol A Chem 204:148-153. https://doi. org/10.1016/j.jphotochem.2009.03.009

206. Popp L, Tran V, Patel R, Segatori L (2018) Autophagic response to cellular exposure to titanium dioxide nanoparticles. Acta Biomater. https://doi.org/10.1016/j.actbio.2018.08.021

207. Lopes VR, Loitto V, Audinot JN, Bayat N, Gutleb AC, Cristobal S (2016) Dose-dependent autophagic effect of titanium dioxide nanoparticles in human $\mathrm{HaCaT}$ cells at non-cytotoxic levels. J Nanobiotechnol 14:1-13. https://doi.org/10.1186/s1295 1-016-0174-0

208. Wei L, Wang J, Chen A, Liu J, Feng X, Shao L (2017) Involvement of PINK1/parkin-mediated mitophagy in $\mathrm{ZnO}$ nanoparticle-induced toxicity in BV-2 cells. Int J Nanomed 12:1891-1903. https://doi.org/10.2147/IJN.S129375

209. Paris I, Perez-Pastene C, Couve E, Caviedes P, LeDoux S, Segura-Aguilar J (2009) Copper dopamine complex induces mitochondrial autophagy preceding caspase-independent apoptotic cell death. J Biol Chem 284:13306-13315. https://doi. org/10.1074/jbc.M900323200

210. Zhang J, Zou Z, Wang B, Xu G, Wu Q, Zhang Y, Yuan Z, Yang $X$, Yu C (2018) Lysosomal deposition of copper oxide nanoparticles triggers HUVEC cells death. Biomaterials 161:228-239. https://doi.org/10.1016/j.biomaterials.2018.01.048

211. Horejsi V (1998) The leucocyte antigen factsbook, 2nd edn. Immunol Today 19:194. https://doi.org/10.1016/s0167 -5699(97)01240-1

212. Xu Y, Wang L, Bai R, Zhang T, Chen C (2015) Silver nanoparticles impede phorbol myristate acetate-induced monocytemacrophage differentiation and autophagy. Nanoscale 7:16100 16109. https://doi.org/10.1039/c5nr04200c

213. Park EJ, Umh HN, Kim SW, Cho MH, Kim JH, Kim Y (2014) ERK pathway is activated in bare-FeNPs-induced autophagy. Arch Toxicol 88:323-336. https://doi.org/10.1007/s0020 4-013-1134-1

214. Johnson BM, Fraietta JA, Gracias DT, Hope JL, Stairiker CJ, Patel PR, Mueller YM, McHugh MD, Jablonowski LJ, Wheatley MA, Katsikis PD (2015) Acute exposure to ZnO nanoparticles induces autophagic immune cell death. Nanotoxicology 9:737748. https://doi.org/10.3109/17435390.2014.974709

215. Roy R, Singh SK, Chauhan LKS, Das M, Tripathi A, Dwivedi PD (2014) Zinc oxide nanoparticles induce apoptosis by enhancement of autophagy via PI3K/Akt/mTOR inhibition. Toxicol Lett 227:29-40. https://doi.org/10.1016/j.toxlet.2014.02.024

216. Kim S, Jang J, Kim H, Choi H, Lee K, Choi I-H (2012) The effects of silica nanoparticles in macrophage cells. Immune Netw 12:296. https://doi.org/10.4110/in.2012.12.6.296

217. Chen L, Liu J, Zhang Y, Zhang G, Kang Y, Chen A (2018) The toxicity of silica nanoparticles to the immune system 13:19391962. https://doi.org/10.2217/nnm-2018-0076

218. Levine B, Kroemer G (2008) Autophagy in the pathogenesis of disease. Cell 132:27-42. https://doi.org/10.1016/j. cell.2007.12.018

219. Lorin S, Hamai A, Mehrpour M, Codogno P (2013) Autophagy regulation and its role in cancer. Semin Cancer Biol 23:361-379. https://doi.org/10.1016/j.semcancer.2013.06.007

220. Chude C, Amaravadi R (2017) Targeting autophagy in cancer: update on clinical trials and novel inhibitors. Int J Mol Sci 18:1279. https://doi.org/10.3390/ijms18061279 